Aus der Poliklinik für Kieferorthopädie

(Prof. Dr. med. dent. D. Kubein-Meesenburg)

im Zentrum Zahn-, Mund- und Kieferheilkunde

der Medizinischen Fakultät der Universität Göttingen

\title{
Kraft- und Drehmomentabgabe thermoplastisch geformter Schienen \\ bei Rotationsbewegung eines Unterkieferfrontzahnes
}

\author{
Inaugural-Dissertation \\ zur Erlangung des Doktorgrades \\ für Zahnheilkunde \\ der Medizinischen Fakultät der \\ Georg-August-Universität zu Göttingen \\ vorgelegt von: \\ Gesa Gruber \\ aus Emden
}

Göttingen 2015 
Dekan

I. Berichterstatter/in:

II. Berichterstatter/in:

III. Berichterstatter/in:

Tag der mündlichen Prüfung:

Prof. Dr. rer. nat. H. K. Kroemer

Priv.-Doz. Dr. med. dent. W. Hahn 


\section{Abkürzungsverzeichnis}

a

Abb.

ANOVA

Bar

bzw.

ca.

CAD

CAM

$\mathrm{cm}^{2}$

et al.

$\mathrm{F}$

g

Max

Min

$\mathrm{ml}$

$\mathrm{mm}$

$\mathrm{n}$

$\mathrm{N}$

$\mathrm{Nmm}$

PETG

PET

$r$

SD

Tab.

$\mathrm{T}$

vgl.

vs.

$\tau$

${ }^{\circ} \mathrm{C}$

3D
Abstand

Abbildung

analysis of variance (Varianzanalyse)

Maßeinheit für den Druck

beziehungsweise

zirka

computer aided design (computergestütztes Konstruieren)

computer aided manufacturing (computergestützte

Fertigung)

Quadratzentimeter

et alii; und andere

force (Symbol für die Kraft)

Gramm

Maximum

Minimum

Milliliter

Millimeter

Anzahl

Newton

Newtonmillimeter

glykolmodifiziertes Polyethylenterephthalat

Polyethylenterephthalat

Radius

standard deviation (Standardabweichung)

Tabelle

Torque (Symbol für das Drehmoment)

vergleiche

versus

griechischer Buchstabe tau. Abkürzung (mathematsich) für Teileranzahlfunktion

Grad Celsius

dreidimensional 


\section{Inhaltsverzeichnis}

1. Einleitung...........................................................................................................................................1

1.1 Orthodontische Therapie mit thermoplastisch geformten Schienen - Entwicklung und

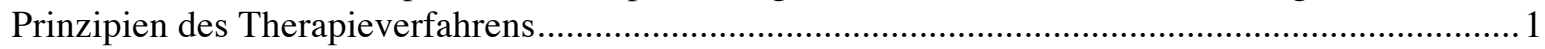

1.2 Indikationsbereich und Nebenwirkungen der Schienentherapie................................................2

1.3 Biomechanische Ansätze des Schienensystems bei der Rotationsbewegung eines

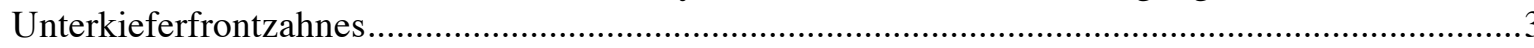

1.4 Auswirkungen kieferorthopädischer Kräfte auf das parodontale Gewebe und apikale

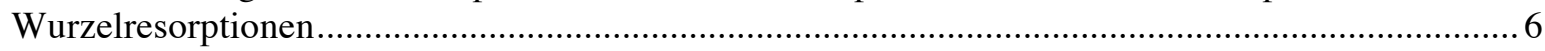

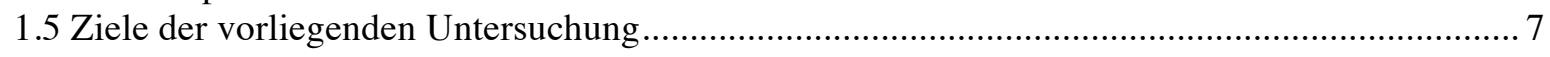

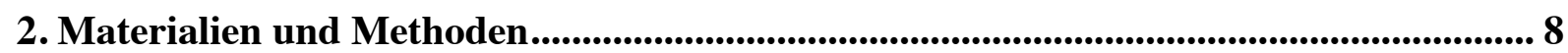

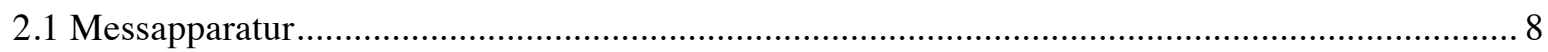

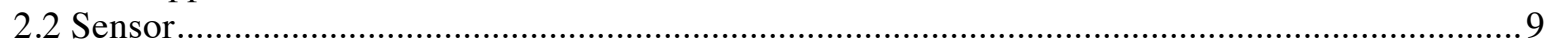

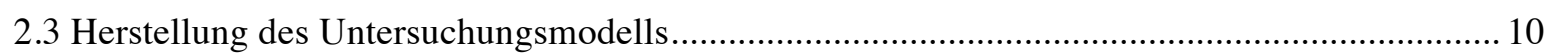

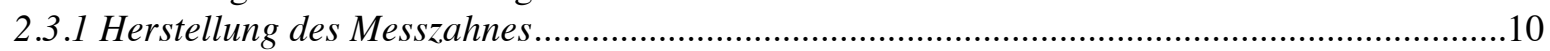

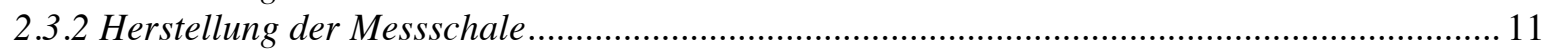

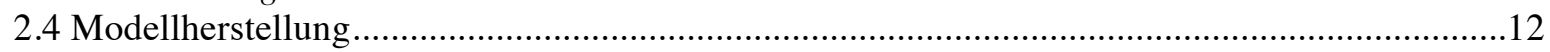

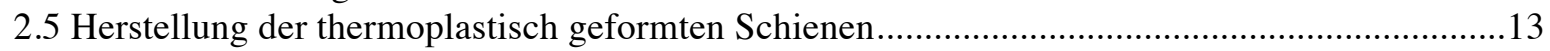

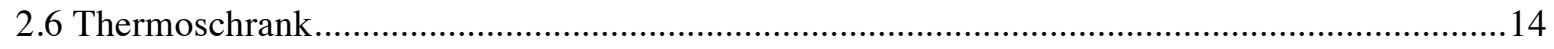

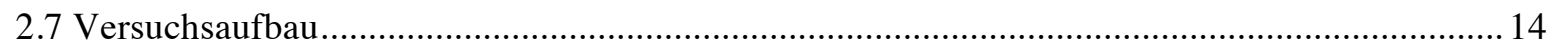

2.8 Messung der von den Schienen ausgehenden Kräfte und Drehmomente................................... 15

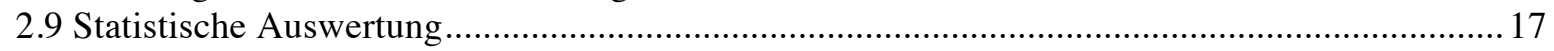

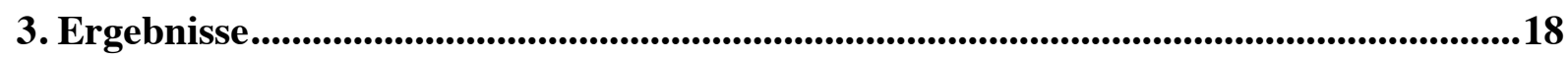

3.1 Ergebnisse der von thermoplastisch geformten Schienen ausgehenden intrusiven

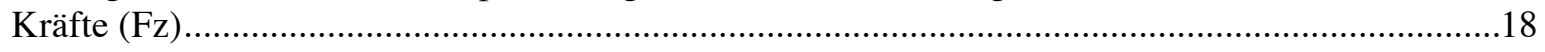

3. 2 Ergebnisse der von thermoplastisch geformten Schienen ausgehenden rotativen

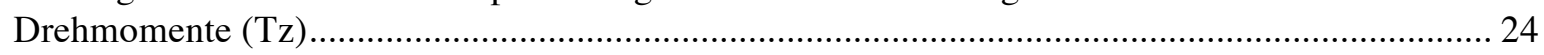

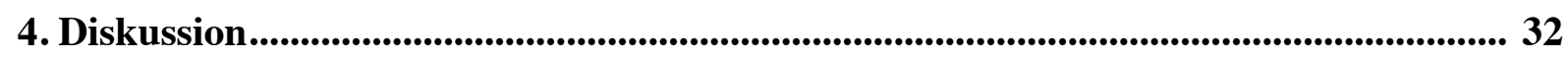

4.1 Entstehung der intrusiven $\mathrm{Kraft}(\mathrm{Fz})$ bei der Rotation eines Unterkieferfrontzahnes

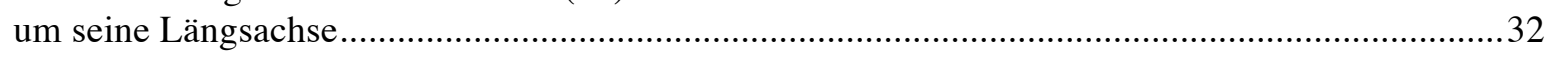

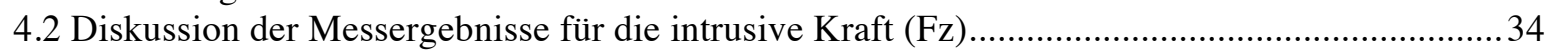

4.3 Diskussion der Messergebnisse für das Drehmoment $(\mathrm{Tz})$........................................................38

4.4 Einfluss der Auslenkungsstrecke auf applizierte Kräfte und Drehmomente in der

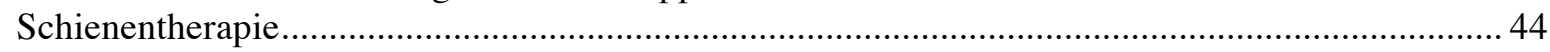

4.5 Einfluss der Materialeigenschaften auf generierte Kräfte und Drehmomente............................46

5. Zusammenfassung. 


\section{Einleitung}

\subsection{Orthodontische Therapie mit thermoplastisch geformten Schienen - Entwicklung und Prinzipien des Therapieverfahrens}

Für eine Standardbehandlung von Zahnfehlstellungen werden zumeist herausnehmbare Platten- und festsitzende Multibandapparaturen eingesetzt. Eine innovative Alternative zu diesen Apparaturen stellen die beinahe unsichtbaren Aligner (thermoplastisch geformte Schienen) dar. Thermoplastisch geformte Schienen werden schon seit einigen Jahrzehnten zur orthodontischen Zahnbewegung verwendet (Kesling 1945, Nahoum 1964, Ponitz 1971, McNamara et al. 1985, Lindauer und Shoff 1998). Zunehmende Aufmerksamkeit wird ihnen seit der Markteinführung der so genannten Invisalign ${ }^{\circledR}$-Schienen in den 1990er Jahren geschenkt. Die Behandlungsmethode, bei der Zähne mit Hilfe einer Serie von thermoplastisch geformten Schienen bewegt werden, beschrieb zuerst Kesling (1945). Seine Idee wurde von verschiedenen Autoren aufgegriffen und weiterentwickelt (Ponitz 1971, McNamara et al. 1985, Sheridan et al. 1993, Sheridan et al. 1994, Rinchuse und Rinchuse 1997).

In der klassischen Methode der Schienentherapie wird zur Herstellung eines Gipsmodells zuerst ein Abdruck der aktuellen Zahnstellung genommen. Die Position der zu bewegenden Zähne wird dann schrittweise auf dem Gipsmodell (Setup-Modell) verändert, bis die angestrebte Idealposition erreicht ist. Für jeden Schritt der Zahnbewegung wird eine neue Schiene hergestellt. Die zur Zahnstellungsänderung erforderliche Kraft resultiert dabei aus der Inkongruenz zwischen der auf dem veränderten Modell geformten Schiene und der IstZahnstellung im Munde des Patienten (Barbagallo et al. 2008a).

Die von Align Technology (Inc. Santa Clara, CA, USA) für die Therapie mit Invisalign ${ }^{\circledR}$ Schienen entwickelte 3D-Methode arbeitet mit der CAD/CAM-Technologie, die ein computergesteuertes Schienendesign und eine computergesteuerte maschinelle Schienenherstellung ermöglicht (Giancotti et al. 2006, Vlaskalic und Boyd 2002). Bei der 3D-Methode werden im Gegensatz zu der klassischen Schienentherapie die erforderlichen Zahnbewegungen virtuell vorgenommen. Zuerst werden die Kieferabformungen der Patienten an AlignTechnology gesandt. Dort wird ein Modell erstellt und mit Hilfe der ClinCheck-Software über eine destruktive Lasertechnik in dreidimensionale Modelle konvertiert (Vlaskalic et al. 2001). Anhand dieser virtuellen Modelle arbeitet AlignTechnology einen Behandlungsplan aus. Wird der Behandlungsplan in der vorgeschlagenen Form vom behandelnden Kieferorthopäden bestätigt, werden stereolithografische Kunststoffmodelle hergestellt, auf 
denen die computergestützte maschinelle Anfertigung der notwendigen Aligner für jeden einzelnen Behandlungsschritt erfolgt (Giancotti et al. 2006, Nedwed und Miethke 2005, Vlaskalic et al. 2001, Boyd et al. 2000, Wong 2002).

Im Gegensatz zu der Behandlung mit festsitzenden Apparaturen sind die Patienten besonders von dem höheren Tragekomfort, den besseren Mundhygienemöglichkeiten und der vorteilhaften Ästhetik der Schienen überzeugt (Djeu et al. 2005). Ein weiterer Vorteil wird in der geringen Beeinträchtigung der Phonetik gesehen (Vlaskalic et al. 2001). Thermoplastisch geformte Schienen müssen fast ganztägig (22 Stunden pro Tag) getragen werden, um ein adäquates Behandlungsergebnis zu erreichen. Eine Kontrolle der Zwischenergebnisse und die Ausgabe der neuen Schienen erfolgt durchschnittlich alle zwei Wochen (Bollen et al. 2003, Vlaskalic et al. 2001). Die Dauer der gesamten Behandlung richtet sich nach dem Ausmaß der Zahnfehlstellung (Joffe 2003).

Um pathologische Nebenwirkungen während der orthodontischen Therapie zu vermeiden, sind die von kieferorthopädischen Apparaturen ausgehenden und auf die zu korrigierenden Zähne einwirkenden Kräfte von großer Bedeutung. Nach heutigem Forschungsstand haben zu hohe Kräfte schädigende Auswirkung auf den Zahn und den Zahnhalteapparat (Barbagallo et al. 2008b, Brezniak und Wasserstein 2008, Casa et al. 2001, Faltin et al. 1998, Harris et al. 2006, Hohmann et al. 2007). Obwohl dieser Zusammenhang wiederholt bestätigt werden konnte, sind die bei der Schienentherapie erzeugten Kräfte bisher in nur wenigen Studien untersucht worden (Kwon et al. 2008, Warunek et al. 1989, Rost et al. 1995, Barbagallo et al. 2008a). Die Untersuchung der von thermoplastisch geformten Schienen ausgehenden Kräfte ist Gegenstand der vorliegenden Arbeit. Exemplarisch werden die Kräfte und Drehmomente untersucht, die bei der Rotationsbewegung eines unteren Schneidezahnes von Alignern erzeugt werden.

\subsection{Indikationsbereich und Nebenwirkungen der Schienentherapie}

Die vollständig entwickelte zweite Dentition stellt die Voraussetzung für eine Behandlung mit thermoplastisch geformten Schienen dar. Über die Indikationsbereiche herrscht jedoch Uneinigkeit unter den Autoren. Sowohl bei weniger schwerwiegenden Zahnfehlstellungen als auch bei komplexen Dysgnathien wird von Behandlungserfolgen berichtet (Miller et al. 2002, Boyd und Vlaskalic 2001, Vlaskalic et al. 2001, Joffe 2003, Chenin et al. 2003).

Hauptsächlich werden moderate Zahnfehlstellungen und Korrekturen von Platzproblemen von ein bis fünf Millimeter, Intrusionen von Frontzähnen zur Korrektur eines Tiefbisses und Kippungen zur Zahnbogenexpansion erfolgreich mit Tiefziehschienen behandelt (Chenin et 
al. 2003, Christensen 2002, Joffe 2003, Lagravère und Flores-Mir 2005). Die Schienentherapie zeigt weiterhin bei der Rotation von Frontzähnen besonders gute Ergebnisse (Kravitz et al. 2008). Das Derotieren zylindrischer Zähne (Eckzähne und Prämolaren) hingegen stellt sich als weniger praktikabel dar (Brezniak 2008). Als schwierig zu behandelnde Fälle werden starke Zahnfehlstellungen, skelettale anterior-posterior Diskrepanzen von mehr als zwei Millimetern, zentrische Relations- und Okklusionsdiskrepanzen, Extrusionen, Molarendistalisierung, kurze klinische Kronen und Rotationen von über $20^{\circ}$ beschrieben (Djeu et al. 2005, Joffe 2003, Vlaskalic und Boyd 2002).

Die besonderen Schwachstellen einer Therapie mit Alignern liegen bei posttherapeutisch offenen Bissen durch Intrusionen unter der Therapie (Vlaskalic und Boyd 2002, Brezniak 2008). Zudem konnte gezeigt werden, dass die Therapie mit thermoplastisch geformten Schienen zu Wurzelresorptionen führen kann, wobei besonders eine intrusiv wirkende Kraft das Risiko erhöht (Brezniak und Wasserstein 2008, Beck und Harris 1994, Dermaut und De Munck 1986, McFadden et al. 1989).

\subsection{Biomechanische Ansätze des Schienensystems bei der Rotationsbewegung eines Unterkieferfrontzahnes}

Wenn Zähne gezielt bewegt werden sollen, ist es von entscheidender Bedeutung, die dafür eingesetzten Kräfte so auf den Zahn wirken zu lassen, dass die gewünschte Endposition des Zahnes auf dem kürzesten und schnellsten Weg mit möglichst geringen Nebenwirkungen erreicht wird.

Zahnbewegungen werden unterteilt in eine Translation (körperliche Zahnbewegung), eine Rotation (Drehung um eine Achse) und eine Kombination aus Translation und Rotation (Smith und Burstone 1984). Ein Zahn wird je nach Lage des Kraftansatzes zum Widerstandszentrum des Zahnes bewegt. Das Widerstandszentrum ist definiert als jener Punkt eines Körpers, der bei einem durch ihn verlaufenden Kraftvektor eine reine Translation bewirkt (Burstone und Pryputniewicz 1980). Bei einwurzeligen Zähnen befindet sich das Widerstandszentrum ungefähr am Übergang vom zervikalen zum mittleren Wurzeldrittel (Burstone und Pryputniewicz 1981). Die Lage des Widerstandzentrums wird beeinflusst von der Länge und Form der Wurzel, von der Attachmenthöhe, der Morphologie des Bindegewebes und des Parodontiums (Kahl-Nieke 2001).

Eine Rotation findet statt, wenn die Kraft nicht durch das Widerstandszentrum geführt wird, sondern an einem beliebigen anderen Punkt des Zahnes ansetzt (Kubein et al. 1984). Von dem Angriffspunkt der Kraft abhängig ist die Lage des Rotationszentrums (Kahl-Nieke 2001). 
Das Produkt aus der Kraft (F) und dem senkrechten Abstand (a) zum Widerstandszentrum bezeichnet man als Drehmoment (vgl. Abb. 1.3.1) (Smith und Burstone 1984). Setzt eine Kraft mit einem bestimmten Abstand zum Widerstandszentrum an, resultiert daraus eine translatorische und eine rotatorische Kraftkomponente.

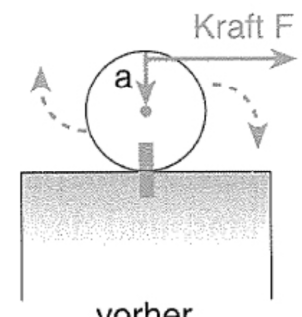

vorher

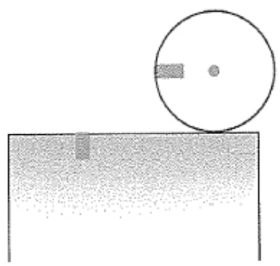

nachher

Abbildung 1.3.1: Drehmoment: Die Kraft F wirkt im Abstand a vom Widerstandszentrum (Kahl-Nieke B 2001,

S. 169, mit freundlicher Genehmigung des Verlages)

Die durch kieferorthopädische Apparaturen applizierten Kräfte setzen an der Krone eines Zahnes, also zwangsläufig mit einem bestimmten Abstand zum Widerstandszentrum, an und können nicht direkt durch das Widerstandszentrum geführt werden, so dass immer eine Kombination aus translatorischer und rotatorischer Kraftkomponente entsteht. Man spricht auch von einem immanenten Drehmoment (Kahl-Nieke 2001).

Die translatorische Kraftkomponente kann theoretisch durch eine gleich große Gegenkraft kompensiert werden, so dass ein Kräftepaar zweier gleich großer entgegengesetzter Kräfte, die parallel verlaufen, erzeugt wird. Auf diese Weise entsteht eine reine Rotationsbewegung (vgl. Abb. 1.3.2). Die durch das Kräftepaar erzeugte Rotationsbewegung könnte wiederum durch eine entsprechende Gegenkraft aufgehoben werden, so dass eine reine Translation resultieren würde (Smith und Burstone 1984). 


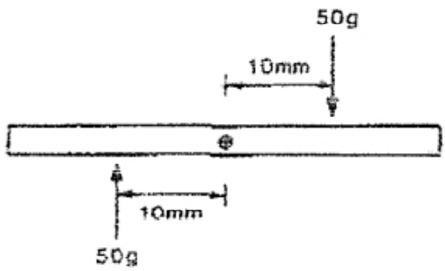

A

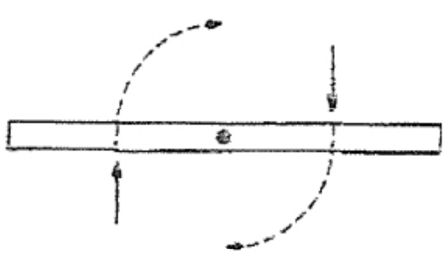

B

Abbildung 1.3.2: A Zwei gleich große, parallel zueinander und in entgegengesetzte Richtungen verlaufende Kräfte $(F)$ bilden ein Kräftepaar; B Die translatorischen Komponenten werden aufgehoben, eine reine Rotation entsteht (Smith und Burstone 1984)

In der vorliegenden Arbeit wurde die Rotationsbewegung eines unteren Frontzahnes simuliert und die dabei von thermoplastisch geformten Schienen ausgehenden Kräfte und Drehmomente untersucht. Die vereinfachte Vorstellung der von Schienen erzeugten Kräfte bei der Rotation eines unteren Frontzahnes wird im Folgenden beschrieben.

In der konventionellen Schienenherstellung wird ein rotierter Zahn aus dem Setup-Modell gelöst und in die gewünschte Position derotiert. Wird nun die thermoplastisch geformte Schiene auf dem veränderten Gipsmodell hergestellt und anschließend auf der Zahnreihe mit der aktuellen Zahnposition platziert, entstehen durch die Inkongruenz zwischen der Form der Schiene und der aktuellen Zahnstellung an dem zu bewegenden Zahn hauptsächlich zwei Kraftansatzpunkte - einer auf der Vestibulär- und einer auf der Lingualfläche des Schneidezahnes. Von inzisal betrachtet, verlaufen die Kraftkomponenten im mesialen Bereich der Schneidekante von lingual nach vestibulär und im distalen Bereich von vestibulär nach lingual. Es entstehen theoretisch zwei gleich große, parallel und in entgegengesetzter Richtung verlaufende Kräfte an dem zu rotierenden Zahn. Dieses Kräftepaar bewirkt theoretisch eine reine Rotationsbewegung um die Längsachse des Zahnes. Diese vereinfachte Vorstellung gleicht der schematischen Darstellung in Abbildung 1.3.2, wenn das rechteckige Objekt in der Abbildung als eine von inzisal betrachtete Schneidekante angenommen wird.

Das Drehmoment ist das Produkt aus dem Abstand von der Rotationsachse zum Ansatzpunkt der Kraft, multipliziert mit der Kraft, die senkrecht zu der Vestibulär- bzw. Lingualfläche des Zahnes ansetzt (vgl. Abbildung 1.3.2).

In der Fachliteratur sind die biomechanischen Hintergründe der orthodontischen Therapie mit Alignern bisher nicht beschrieben worden. In der Studienserie von Hahn (Hahn 2009, Hahn et al. 2009a, 2009b, 2010a, 2010b, 2011, Engelke 2010, Seiffert 2012, Erfurth-Jach 2012), zu der auch die vorliegende Arbeit gehört, wurde erstmals die Kraftabgabe thermoplastisch 
geformter Schienen systematisch untersucht. Die durch die Schienen erzeugten Kräfte wurden dabei bei unterschiedlichen Schienenstärken sowie bei unterschiedlichen Materialien und Bewegungsformen analysiert.

\subsection{Auswirkungen kieferorthopädischer Kräfte auf das parodontale Gewebe und apikale} Wurzelresorptionen

Jeder Zahn ist über einen Bandapparat im Parodontalspalt zwischen Zahn und Alveolarknochen (parodontales Ligament) beweglich aufgehängt (Rosenbauer et al. 1998). Grundsätzlich ist es durch die im Folgenden beschriebenen zellulären Reaktionen auf eine mechanische Belastung hin möglich, einen Zahn durch kieferorthopädische Kräfte durch den Knochen $\mathrm{zu}$ bewegen. Eine am Zahn ansetzende Kraft, die beispielsweise durch kieferorthopädische Apparaturen erzeugt wird, wirkt sowohl auf den Zahn als auch auf die angrenzenden Strukturen. Es entstehen Druckzonen, in denen der Alveolarknochen belastet und dadurch der Parodontalspalt verengt wird und Zugzonen, in denen der Parodontalspalt erweitert und dadurch die Parodontalfasern gespannt werden (von Böhl und Kuijpers-Jagtman 2009). Diese biophysikalischen Veränderungen im Parodont führen zu einer Umwandlung der frei werdenden mechanischen Energie in biologische Signale (Roberts et al. 1981). Über verschiedene Schlüsselmoleküle bewirkt die kraftinduzierte Kompression des parodontalen Ligaments die Umwandlung von Progenitorzellen in knochenabbauende Osteoklasten und knochenanbauende Osteoblasten, die den morphologischen Umbauprozess des Zahnhalteapparates und letztendlich die Zahnbewegung einleiten (Masella und Meister 2006, Roberts et al. 1981). In den Zugzonen findet eine Knochenapposition und in den Druckzonen eine Knochenresorption statt (Roberts et al. 1981). Bei der orthodontischen Zahnbewegung wird die so genannte direkte Knochenresorption angestrebt. Diese resultiert aus einer leichten Kompression des parodontalen Ligaments durch geringe kieferorthopädische Kräfte, so dass die Blutzirkulation erhalten bleibt (Schopf 2000).

Im Gegensatz dazu wird bei zu hoher Krafteinwirkung die Blutzirkulation des Ligaments gestört oder gar vollständig unterbrochen. Dies führt durch die Hyalinisation (Zelltod) des Gewebes $\mathrm{zu}$ einer verlangsamten oder stagnierenden orthodontischen Zahnbewegung. In dieser Situation spricht man von der indirekten oder unterminierenden Knochenresorption (Schopf 2000, Reitan 1951, Reitan 1960, Rygh 1973, Schwarz 1932). Bei anhaltend unterbrochener Blutzirkulation entstehen Nekrosen in den betroffenen Gewebebereichen. Die nekrotischen Bereiche aktivieren makrophagenähnliche Zellen, die die geschädigten Bereiche eliminieren (Brezniak und Wasserstein 2002). Während des Abbauprozesses der an die 
Wurzelhaut angrenzenden Nekrosen und Hyalinisierungszonen kommt es unter Umständen zum Abbau der Zahnwurzel, einer so genannten orthodontisch induzierten, entzündlichen Wurzelresorption (Roberts et al. 1987, Brezniak und Wasserstein 2002, Brudvik und Rygh 1994, 1995).

\subsection{Ziele der vorliegenden Untersuchung}

Häufig werden thermoplastisch geformte Schienen zur Korrektur von Rotationen der Frontzähne eingesetzt. Bisher konnte jedoch nicht geklärt werden, welche Kräfte und Drehmomente bei der Therapie dieser Fehlstellung mittels Alignern auf einen unteren Schneidezahn einwirken.

Ziel der vorliegenden Untersuchung war es deshalb, die von thermoplastisch geformten Schienen erzeugten Kräfte und Drehmomente bei der Rotationsbewegung eines unteren seitlichen Schneidezahnes zu messen. Der Einfluss der Auslenkungsstrecke und die Abhängigkeit vom Schienenmaterial werden dabei im Besonderen betrachtet.

Die für diese Untersuchung entwickelte Messapparatur erlaubt die getrennte Messung einzelner Kraftkomponenten, so dass eine Aufschlüsselung der horizontalen und vertikalen Kräfte und der auftretenden Drehmomente möglich war. In der vorliegenden Studie werden die intrusive Kraft und das rotative Drehmoment betrachtet. 


\section{Materialien und Methoden}

Die in dieser Untersuchung eingesetzte modulare In-vitro-Messapparatur erfasst die von thermoplastisch geformten Schienen ausgehenden Kräfte und Drehmomente. Die Messapparatur besteht aus einem Metallrahmen, auf dem eine Kunststoffschale mit einem Kunststoffkiefermodell fixiert wird. Auf der Bodenplatte des Metallrahmens wird der Sensor zur Erfassung der Kräfte und Drehmomente befestigt. Der Messzahn wird in die Zahnreihe des Kiefermodells integriert und über eine Klemmvorrichtung mit dem Sensor verbunden. Er wird in der vorliegenden Untersuchung um eine Achse rotiert, die durch das Zentrum der Inzisalkante und die horizontale Wurzelmitte des Messzahnes verläuft. Die von dem Sensor abgehenden Messdaten werden mit Hilfe einer Software in Kraft- und Drehmomentkomponenten umgerechnet. Zur Simulation der Körpertemperatur wird das Untersuchungsmodell an die Kammer eines Thermoschrankes angeschlossen.

Im Folgenden werden der Aufbau der Messapparatur, einzelne Bestandteile der Messapparatur, die Modell- und Schienenherstellung sowie der Versuchsablauf detailliert beschrieben.

\subsection{Messapparatur}

Der Metallrahmen der Messapparatur besteht aus Hartaluminium und ist über vier Rundstäbe mit einer Bodenplatte verbunden. Der Aluminiumrahmen ermöglicht die reversible Aufnahme einer Kunststoffschale, die durch eine Klemmschraube in gewünschter Position arretiert wird. Die Kunststoffschale dient der Aufnahme des Untersuchungsmodells, welches zuvor mit Gips in der Kunststoffschale befestigt wurde. Bei dem hier verwendeten Untersuchungsmodell handelt es sich um ein idealisiertes Unterkiefermodell aus Kunststoff eines 15-jährigen zahngesunden jungen Mannes (frasaco GmbH, Tettnang, Deutschland).

Der Messzahn wird mit Hilfe eines Gipsschlüssels in die durch diesen vorgegebene Position in der Kunststoffzahnreihe des Untersuchungsmodells eingegliedert. Auf der Bodenplatte wird ein Präzisionsstelltisch (DT 130 OWIS GmbH, Staufen, Germany) positioniert und angeschraubt. Eine auf dem Präzisionsstelltisch befestigte Metallplatte erlaubt die Befestigung des Sensors. Der Messzahn wird für die Messungen über eine Klemmvorrichtung mit dem Sensor verbunden. 


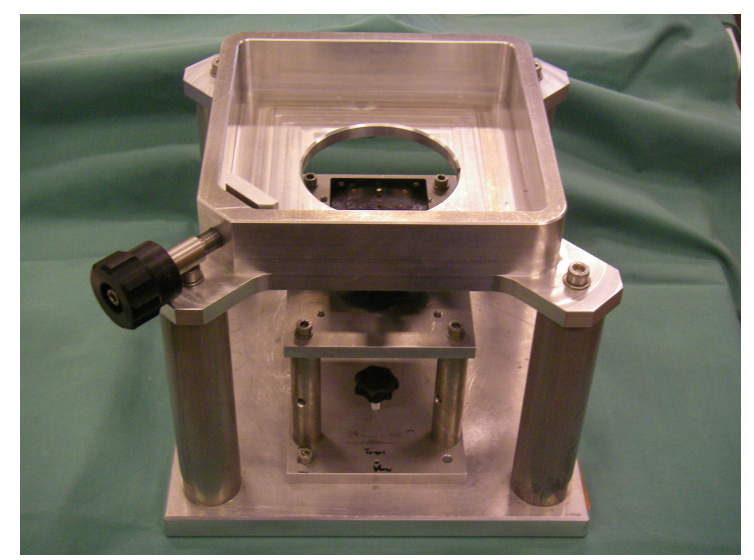

Abb. 2.1.1: Der Aluminiumrahmen zur Aufnahme einer Kunststoffschale. Auf der Bodenplatte wird der Präzisionsstelltisch befestigt.

\subsection{Sensor}

Der in dieser Untersuchung eingesetzte Sensor (Nano 17, ATI Industrial Automation, Apex, USA) ermöglicht das Erfassen von Kräften und Drehmomenten in allen drei Richtungen des Raumes. Ihm liegt als Funktionsprinzip ein monolithischer Messkörper mit drei Messsträngen zu Grunde.

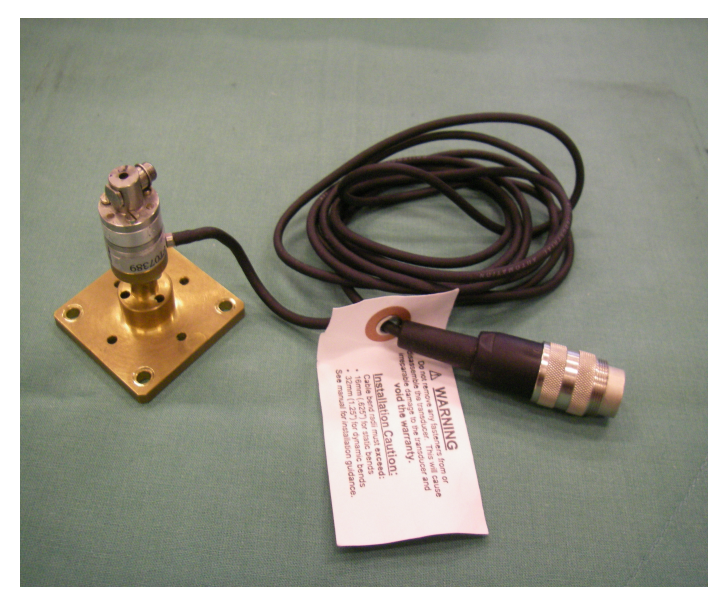

Abbildung 2.2.1: Der Nano 17 Sensor. Eine Klemmvorrichtung am oberen Ende dient der Aufnahme eines Messzahnes. Über den Metallfuß wird der Sensor reversibel an einem Positionierungstisch befestigt.

Über jeweils zwei Dehnmessstreifen aus Silikon erfassen die Messstränge Verformungen im Mikrometerbereich.

Die von dem Sensor über die Dehnmessstreifen abgehenden analogen Messwerte werden über die verwendete Software (ATI DAQ F/T Demo Software, Version 1.2.4.) in drei Kraft- (Fx, Fy, Fz) und drei Drehmomentkomponenten (Tx, Ty, Tz) umgewandelt. 
Das Drehmoment errechnet sich aus der aufgebrachten Kraft (statisch und dynamisch) multipliziert mit dem Hebelarm. Der Hebelarm ergibt sich aus der Distanz vom Angriffspunkt der Kraft bis zum Nullpunkt des Sensors.

Der Sensor weist unterschiedlich optimale Mess- und Überlastsicherheitsbereiche für die drei Kraftkomponenten auf. Für Fx und Fy beträgt der optimale Messbereich $\pm 12 \mathrm{~N}$ bei einer Überlastsicherheit von \pm 350 N. Für Fz liegt der optimale Messbereich bei $\pm 17 \mathrm{~N}$ bei einer Überlastsicherheit von $\pm 800 \mathrm{~N}$.

Für Tx, Ty, Tz liegt der optimale Messbereich bei \pm 120 Nmm.

\subsection{Herstellung des Untersuchungsmodells}

\subsubsection{Herstellung des Messzahnes}

Der aus der Zahnreihe des Kunststoffmodells herauslösbare Messzahn ist vor seiner Bearbeitung für die Messungen ein Teil des Unterkieferkunststoffmodells gewesen. Um während der Messdurchläufe eine absolute Bewegungsfreiheit des Zahnes zu gewährleisten wurde der Teil des Modells herausgesägt, der der Verschraubung des Zahnes im Modell dient. Um eine eindeutige Repositionierung des Messzahnes im Unterkiefermodell zu gewährleisten, wurde ein Repositionierungsschlüssel aus Gips (Dentalgips Klasse V, GC Fujirock $^{\circledR}$ EP, GC Germany GmbH, München, Deutschland) angefertigt.

Der Messzahn wurde wie folgt vorbereitet: Die Wurzel des Messzahnes wurde bis auf $1 \mathrm{~mm}$ unterhalb der vestibulären Schmelzzementgrenze gekürzt. Mit Hilfe eines Gerätes zur optischen Vermessung (Peak TM Zoomlupe 816, YAM POK (H.K.) Technology Limited, Hongkong, China) wurden auf der Schnittfläche der abgetrennten Wurzel und auf der Schneidekante des Messzahnes jeweils die Mittelpunkte bestimmt. Hier wurden kleine Löcher als Markierung zur späteren Aufnahme der Zentrierungsspitzen des Zentrierungsapparates angelegt. Der Zentrierungsapparat erlaubt die Simulation einer reinen Rotation des Messzahnes. Er besteht aus zwei Halbschalen, die miteinander verschraubt eine Hohlform ergeben.

Der vorbereitete Zahn wurde mit Hilfe der Zentrierungsspitzen im Zentrum der Hohlform platziert. Nachdem der Zahn in seiner Rotationsachse positioniert war, wurden die beiden Halbschalen wieder verschraubt. Nun wurde die Hohlform mit dem sich darin befindlichen Messzahn mit Gips (GC Fujirock ${ }^{\circledR}$ EP, GC Germany, GmbH, München, Deutschland) ausgegossen. Nachdem der Gips ausgehärtet war, konnten die beiden Halbschalen wieder voneinander gelöst werden, um den in der Hohlform befindlichen Gipszylinder zu entnehmen 
und diesen mit Hilfe eines Dreibackenfutters achsenzentriert in eine Präzisionsdrehbank (Condor, Weiler Werkzeugmaschinen, Emskirchen, Deutschland) einzuschrauben.

Mit einem HSS-Spiralbohrer wurde eine Normbohrung $(\varnothing 2,5 \mathrm{~mm})$ an der Unterseite des Messzahnes angelegt. Der Bohrer wurde nach Anlegen von Retentionsrillen mit Kunststoff (Weitur ${ }^{\circledR}$ Press, Johannes Weithas Dental-Kunststoffe, Lütjenburg, Deutschland) in die Normbohrung einpolymerisiert.

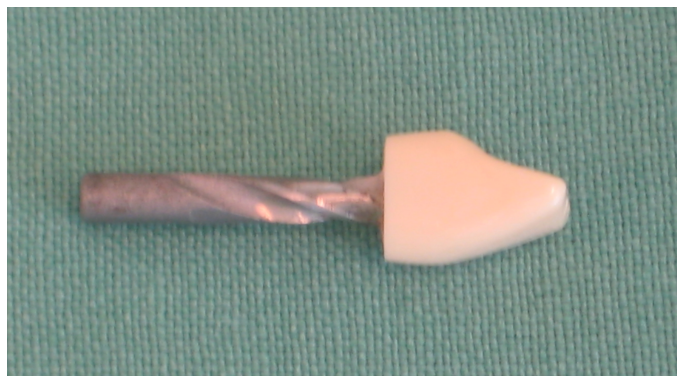

Abbildung 2.3.1: Messzahn mit einpolymerisiertem Bohrerschaft

Um einen möglichst kurzen Hebelarm zu erreichen, wurde der Schaft des Bohrers so weit gekürzt, dass der Abstand zwischen Sensor und Zahn $1 \mathrm{~mm}$ und die Gesamtlänge des Messzahnes insgesamt 23,66 mm betrug.

\subsubsection{Herstellung der Messschale}

Die Kunststoffschale dient der Aufnahme des Untersuchungsmodells, in welches der Messzahn für die Messungen integriert wird. Damit eine Verbindung zwischen Sensor und Modell hergestellt werden kann, wurde zuerst ein Loch in die Kunststoffschale gefräst. Die Kunststoffschale wurde dann in dem Metallrahmen der Messapparatur positioniert. Mit Hilfe des zuvor hergestellten Gipsschlüssels wurde der Messzahn mit Hartklebewachs (Deiberit 502, Siladent Dr. Böhme \& Schöps GmbH, Goslar, Deutschland) in vorgegebener Position zum Modell fixiert. Das Modell wurde innerhalb der Kunststoffschale positioniert und über eine Klemmvorrichtung arretiert, so dass eine starre Verbindung zwischen Modell, Zahn und Sensor entsteht. In der so festgelegten Position wurde das Modell in der Kunststoffschale mit Superhartgips (GC Fujirock ${ }^{\circledR}$ EP, GC Germany, GmbH, München, Deutschland) fixiert (vgl. Abb. 2.3.2). 


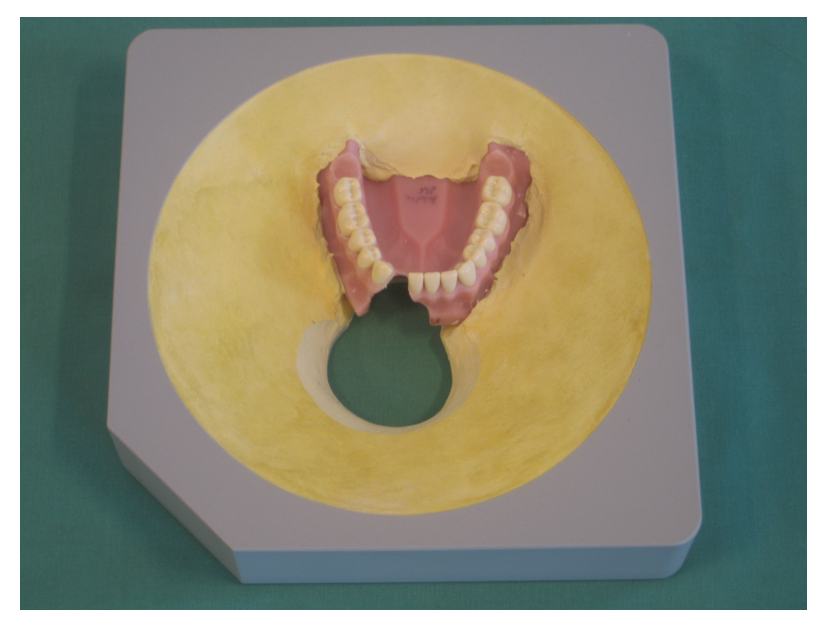

Abbildung 2.3.2: Kunststoffschale mit eingegipstem Untersuchungsmodell. Der Messzahn ist hier herausgelöst. Die Aussparung ermöglicht die Verbindung des Sensors mit dem Messzahn, der mit Hilfe eines Repositionierungsschlüssels platziert wird.

\subsection{Modellherstellung}

Für die Herstellung des Urmodells, das der Erstellung der Gipsmodelle dient, die wiederum zur Schienenherstellung verwendet werden, wurde der Messzahn im Zahnkranz des Versuchsmodells befestigt. Der Gingivaverlauf am Zahn wurde mit Modellierwachs rekonstruiert, um eine eindeutige Referenzlinie für die Schienenherstellung zu erhalten und unter sich gehende Bereiche bei der Abformung zu verhindern. Das Abdruckmaterial Alginat Tetrachrom $^{\circledR}$ (Kanidenta, Herford, Deutschland) wurde mit dem Alginatanmischgerät (Hauschild \& Co. GmbH, Döbeln, Deutschland) angerührt und eine Abformung des Modells genommen. Der Abdruck wurde anschließend mit Dentalgips der Klasse IV (GC Fujirock ${ }^{\circledR}$ EP, GC Germany GmbH, München, Deutschland) im Verhältnis 20 ml Flüssigkeit zu 100 g Pulver ausgegossen. Hierfür wurde der Gips für ca. 30 Sekunden mit einem Vakuumanmischgerät angerührt. Nachdem der Gips ausgehärtet war, wurde das entstandene Gipsmodell aus der Abdruckmasse gelöst. Überschüssiger Gips wurde mit Gipsfräsen entfernt und das gesamte Modell parallel zur Okklusionsebene auf eine Höhe von 20 mm getrimmt. Um möglichst gleiche Voraussetzungen für die spätere Schienenherstellung zu schaffen, wurde für jeden Herstellungsvorgang ein eigenes Gipsmodell angefertigt.

Zur Vervielfältigung des Gipsmodelles wurde eine Dublierform aus Adisil ${ }^{\circledR}$ blau 9:1 (Siladent Dr. Böhme \& Schöps GmbH, Goslar, Deutschland) angefertigt. Mit dieser wurden 20 Modelle aus Dentalgips der Klasse IV (GC Fujirock ${ }^{\circledR}$ EP, GC Germany GmbH, München, Deutschland) hergestellt und ebenfalls parallel zur Okklusionsebene auf $20 \mathrm{~mm}$ Höhe getrimmt. 


\subsection{Herstellung der thermoplastisch geformten Schienen}

Die zu untersuchenden Schienen wurden aus folgenden vier Materialien hergestellt: Biolon ${ }^{\circledR}$ 1,0 mm (Dreve Dentamid GmbH, Unna, Deutschland), Erkodur ${ }^{\circledR}$ 1,0 mm (Erkodent ${ }^{\circledR}$ Erich Kopp GmbH, Pfalzgreifenweiler, Deutschland), Ideal Clear ${ }^{\circledR}$ 1,0 mm (Dentsply GAC, Gräfelfing, Deutschland), Ideal Comfort ${ }^{\circledR}$ 1,0 mm (Dentsply GAC, Gräfelfing, Deutschland). Die Millimeterangabe gibt jeweils die Stärke des Materials an. Die Schienen bestehen aus modifiziertem Polyethylenterephthalat (PET) $\left(\right.$ Biolon $\left.^{\circledR}\right)$, glykolmodifiziertem Polyethylenterephtalat (PETG) $\left(\right.$ Erkodur $\left.^{\circledR}\right)$ und Polyester auf Terephtalatsäurebasis (Ideal Clear ${ }^{\circledR}$ und Ideal Comfort ${ }^{\circledR}$ ).

Für den Herstellungsprozess der Schienen empfehlen die jeweiligen Hersteller unterschiedliche Tiefziehverfahren und -geräte, die in Tabelle 2.5.1 zusammengefasst sind.

Alle Schienenmaterialien werden zunächst erwärmt, um sie in einen plastisch verformbaren Zustand $\mathrm{zu}$ überführen. Anschließend werden sie je nach Tiefziehverfahren auf das Gipsmodell gepresst (Drufomat-TE) oder über die Vakuumtechnik auf das Modell gesaugt (Vacuum Forming Machine 202, Erkoform RVE) (vgl. Tab. 2.5.1).

\begin{tabular}{|c|c|c|c|}
\hline Schienenmaterialien & Tiefziehverfahren & $\begin{array}{c}\text { Name und } \\
\text { Herstellerangaben } \\
\text { der Gerätes }\end{array}$ & Druck (Bar) \\
\hline $\begin{array}{c}\text { Ideal Clear }^{\circledR} \\
\text { Ideal Comfort }^{\circledR}\end{array}$ & Vakuum & $\begin{array}{l}\text { Vacuum Forming } \\
\text { Machine } 202 \\
\text { (Dentsply GAC, } \\
\text { Gräfelfing, } \\
\text { Deutschland) }\end{array}$ & 0,8 \\
\hline Erkodur $^{\circledR}$ & Vakuum & $\begin{array}{l}\text { Erkoform RVE } \\
\text { (Erkodent }^{\circledR}, \text { Erich } \\
\text { Kopp GmbH, } \\
\text { Pfalzgreifenweiler, } \\
\text { Deutschland) }\end{array}$ & 0,8 \\
\hline Biolon $^{\circledR}$ & Druck & $\begin{array}{l}\text { Drufomat-TE } \\
\text { (Dreve Dentamid } \\
\text { GmbH, Unna, } \\
\text { Deutschland) }\end{array}$ & 6 \\
\hline
\end{tabular}

Tabelle 2.5.1: Für den Herstellungsprozess der untersuchten Schienenmaterialien werden Vakuumgeräte und Druckgeräte verwendet.

Jede Schiene wurde nach dem Herstellungsvorgang mit dem HSS-Spiralbohrer und einer Lisko-S Polierscheibe (Erkodent ${ }^{\circledR}$ Erich Kopp GmbH, Pfalzgreifenweiler, Deutschland) 
ausgearbeitet. Als Referenzlinie für den Schienenrand wurde die marginale Gingiva herangezogen (vgl. Abb. 2.5.1).

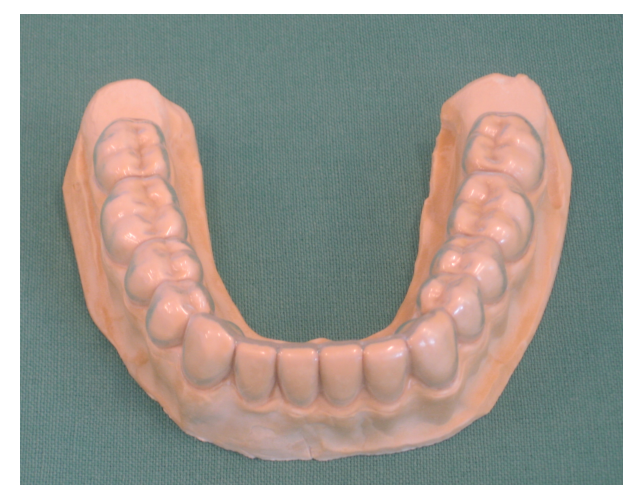

Abbildung 2.5.1: Ausgearbeitete Kunststoffschiene auf einem Gipsmodell. Der Rand der marginalen Gingiva dient als Referenzlinie für den Schienenrand.

\subsection{Thermoschrank}

Zur Simulation der intraoralen Temperatur von ca. $37^{\circ} \mathrm{C}$ wurde die Messapparatur an einen Thermoschrank Typ HTD 50 (Flohr Instruments, Utrecht, Niederlande) angeschlossen. Hierfür befindet sich ein Loch im Boden des Thermoschranks. Die Kunststoffschale mit der gesamten Messapparatur wurde unterhalb des Thermoschranks platziert und mit Hilfe eines Hubtisches so positioniert, dass das Untersuchungsmodell durch das Loch in die Kammer des Thermoschranks hineinragte. Die runde Öffnung im Boden des Thermoschrankes schließt mit der Kunststoffschale dicht ab.

\subsection{Versuchsaufbau}

Vor den Messungen wurde der Messapparat wie folgt vorbereitet: Die Kunststoffschale wurde in dem Metallrahmen fixiert und die einzelnen Komponenten der Messapparatur miteinander verzapft und verschraubt. Danach wurde der Messzahn in die von dem Gipsschlüssel vorgegebene Position gebracht und über die Klemmvorrichtung mit dem Sensor verbunden (vgl. Abb. 2.7.1). 


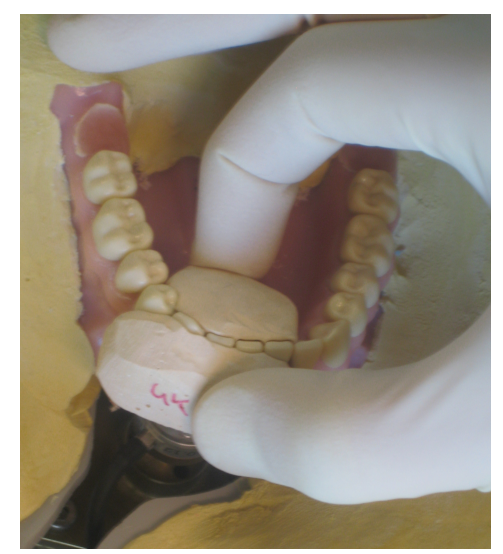

Abbildung 2.7.1: Positionierung des Messzahnes mit Hilfe des Gipsschlüssels

Die Messapparatur wurde an die Kammer des Thermoschrankes angeschlossen, welcher vor den Messungen auf eine Temperatur von ca. $37^{\circ} \mathrm{C}$ gebracht wurde.

\subsection{Messung der von den Schienen ausgehenden Kräfte und Drehmomente}

Für die vorliegende Studie haben insgesamt 20 Schienen aus vier verschiedenen Materialien den Messzyklus durchlaufen.

Jede Schiene wurde vor den Messungen mit zwei Sprühstößen künstlichen Speichels (Universitätsapotheke Göttingen) benetzt. Bei Applikation einer Schiene auf das Untersuchungsmodell befand sich der Messzahn in Nullposition.

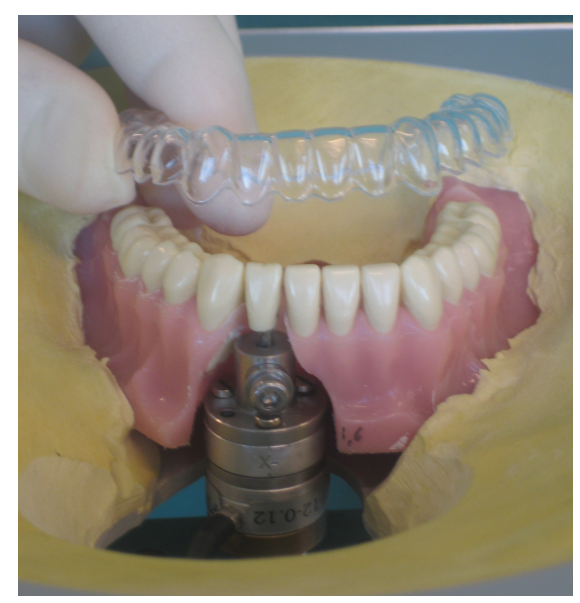

Abbildung 2.8.1: Aufsetzen einer Schiene auf das mit dem Sensor verbundene Unterkiefermodell

Vor jedem Messdurchlauf wurden alle Kräfte und Drehmomente über die Software genullt. 


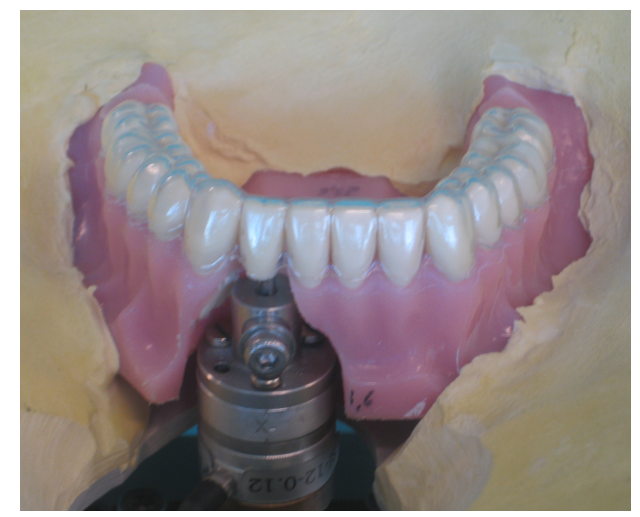

Abbildung 2.8.2: Eingegliederte Schiene und das mit dem Sensor verbundene Untersuchungsmodell

Der Messdurchlauf einer Schiene beinhaltete die Rotation des Messzahnes in 0,5 - Schritten von $0^{\circ}$ auf $10^{\circ}$ (hin) und wieder auf $0^{\circ}$ (rück). Danach wurde die Rotation des Zahnes in entgegengesetzter Richtung von $0^{\circ}$ auf $-10^{\circ}$ (hin) und wieder auf $0^{\circ}$ (rück) durchgeführt. Nach jedem neu eingestellten $0,5^{\circ}$-Schritt wurden die Kräfte (Fx, Fy, Fz) und Drehmomente (Tx, Ty, Tz) aufgezeichnet und von der DAQ F/T-Software gespeichert. Für jeden Rotationsschritt wurden fünf Messergebnisse aufgezeichnet. Zwischen den Rotationsschritten lag ein konstantes Zeitintervall von 30 Sekunden.

Jeder Auslenkungswinkel wurde zur besseren Vergleichbarkeit mit anderen Werten über die Formel $2 \cdot \tau \cdot r=360^{\circ}(r=2,575 \mathrm{~mm})$ in Auslenkungsstrecken $(\mathrm{mm})$ der äußersten mesialen und distalen Endpunkte der Inzisalkante des Messzahnes umgerechnet.

Für die vorliegende Untersuchung werden die initialen intrusiven Kräfte (Fz) und rotativen Drehmomente (Tz) für die Rotationswinkel 3,5 $5^{\circ}$ (hin), $8^{\circ}$ (hin), $-3,5^{\circ}$ (hin) und $-8^{\circ}$ (hin) betrachtet. Diese entsprechen den Auslenkungsstrecken 0,157 mm, 0,360 mm, -0,157 mm und $-0,360 \mathrm{~mm}$. Die negativen Vorzeichen kennzeichnen die Rotationsrichtung des Messzahnes mit dem Uhrzeigersinn ( $-3,5^{\circ}$ bzw. $-0,157$ und $-8^{\circ}$ bzw. $\left.-0,360 \mathrm{~mm}\right)$.

Folgende Teiluntersuchungen werden durchgeführt:

1. Messung der bei einer Rotationsbewegung von thermoplastisch geformten Schienen ausgehenden intrusiven Kräfte (Fz)

1a. Messung und Vergleich der intrusiven Kräfte (Fz) in Abhängigkeit von vier verschiedenen gleich starken Schienenmaterialien 
1b. Messung und Vergleich der intrusiven Kräfte $(\mathrm{Fz})$ in Abhängigkeit von den Aktivierungsstrecken $0,157 \mathrm{~mm},-0,157 \mathrm{~mm}, 0,360 \mathrm{~mm}$ und $-0,360 \mathrm{~mm}$

2. Messung der bei einer Rotationsbewegung von thermoplastisch geformten Schienen ausgehenden rotativen Drehmomente $(\mathrm{Tz})$

2a. Messung und Vergleich der rotativen Drehmomente $(\mathrm{Tz})$ in Abhängigkeit von den vier verschieden Schienenmaterialien

2b. Messung und Vergleich der rotativen Drehmomente $(\mathrm{Tz})$ in Abhängigkeit von den Aktivierungsstrecken $0,157 \mathrm{~mm},-0,157 \mathrm{~mm}, 0,360 \mathrm{~mm}$ und $-0,360 \mathrm{~mm}$

\subsection{Statistische Auswertung}

Die erfassten Kräfte und Drehmomente wurden mit dem Programm SAS (9.1.1, Cary, USA) statistisch ausgewertet.

Zunächst wurde eine zwei- und für die Paarvergleiche eine einfaktorielle analysis of variance (ANOVA) mit Messwiederholungen durchgeführt. Beide Modelle wurden mit dem Material und dem Winkel als feste Effekte und den Schienen als zufällige Effekte durchgeführt.

In dem zweifaktoriellen gemischten linearen Modell mit Messwiederholungen wurde der Einfluss der Faktoren „Material“ und „Winkel“, in dem einfaktoriellen gemischten linearen Modell der Einfluss des Faktors „Material“ analysiert. Bei der einfaktoriellen Analyse wurde nach Winkeln aufgesplittet.

Die gemischten linearen Modelle wurden mit Messwiederholungen durchgeführt, was die fünf Messwiederholungen pro Schiene berücksichtigt.

Die Ursprungsdaten waren nicht normal verteilt, was als Vorraussetzung für die Analyse mit linearen Modellen gegeben sein muss. Deshalb wurden die linearen Modelle auf Rängen basierend durchgeführt. Die Ränge wurden mit dem SAS Programm über die Beobachtungen gebildet. Für multiple Vergleiche wurde nach der Turkey-Methode adjustiert.

Ein Teil der statistischen Ergebnisse wurde mittels Box-Whisker-Plots über das Programm Statistica (Statistica 8.0, Tulsa, USA) visualisiert. Für die Herstellung der Grafiken wurden die über die Messwiederholungen einer Schiene gemittelten Werte verwendet. 


\section{Ergebnisse}

Es wurden die vertikalen Kräfte $(\mathrm{Fz})$ und rotativen Drehmomente $(\mathrm{Tz})$ in Abhängigkeit von den Aktivierungsstrecken $0,157 \mathrm{~mm},-0157 \mathrm{~mm}, 0,360 \mathrm{~mm}$ und $-0,360 \mathrm{~mm}$ gemessen, die bei der Rotation eines unteren seitlichen Schneidezahnes von thermoplastisch geformten Schienen unterschiedlicher Materialien ausgehen.

Die negativen Vorzeichen sind bei den Werten für Fz Ausdruck der Kraftrichtung nach apikal und bei den Werten für Tz Ausdruck der Richtung des Drehmoments. Negative Vorzeichen vor den Auslenkungsstrecken kennzeichnen die Rotationsrichtung des Messzahnes mit dem Uhrzeigersinn.

\subsection{Ergebnisse der von thermoplastisch geformten Schienen ausgehenden intrusiven}

Kräfte (Fz)

\begin{tabular}{|c|c|c|c|c|c|c|c|}
\hline Material & Stärke & $\mathbf{n}$ & Strecke (mm) & $\operatorname{Mean}(\mathbf{N})$ & $\operatorname{Max}(\mathbf{N})$ & $\operatorname{Min}(\mathbf{N})$ & SD \\
\hline Biolon $^{\circledR}$ & $1 \mathrm{~mm}$ & 5 & 0,157 & $-1,66$ & $-3,50$ & $-0,30$ & 1,32 \\
\hline Biolon $^{\circledR}$ & $1 \mathrm{~mm}$ & 5 & 0,360 & $-5,15$ & $-7,45$ & $-3,76$ & 1,46 \\
\hline Biolon $^{\circledR}$ & $1 \mathrm{~mm}$ & 5 & $-0,360$ & $-5,81$ & $-6,62$ & $-5,19$ & 0,56 \\
\hline Biolon $^{\circledR}$ & $1 \mathrm{~mm}$ & 5 & $-0,157$ & $-1,52$ & $-2,51$ & $-1,04$ & 0,59 \\
\hline Ideal Clear $^{\circledR}$ & $1 \mathrm{~mm}$ & 5 & 0,157 & $-1,69$ & $-2,10$ & $-0,81$ & 0,52 \\
\hline Ideal Clear ${ }^{\circledR}$ & $1 \mathrm{~mm}$ & 5 & 0,360 & $-5,12$ & $-5,90$ & $-3,97$ & 0,71 \\
\hline Ideal Clear ${ }^{\circledR}$ & $1 \mathrm{~mm}$ & 5 & $-0,360$ & $-4,92$ & $-5,94$ & $-3,73$ & 0,95 \\
\hline Ideal Clear ${ }^{\circledR}$ & $1 \mathrm{~mm}$ & 5 & $-0,157$ & $-1,14$ & $-2,09$ & 0,11 & 0,99 \\
\hline Erkodur $^{\circledR}$ & $1 \mathrm{~mm}$ & 5 & 0,157 & $-0,70$ & $-1,56$ & $-0,26$ & 0,52 \\
\hline Erkodur $^{\circledR}$ & $1 \mathrm{~mm}$ & 5 & 0,360 & $-3,15$ & $-3,64$ & $-2,71$ & 0,35 \\
\hline Erkodur $^{\circledR}$ & $1 \mathrm{~mm}$ & 5 & $-0,360$ & $-3,91$ & $-4,33$ & $-3,51$ & 0,30 \\
\hline Erkodur $^{\circledR}$ & $1 \mathrm{~mm}$ & 5 & $-0,157$ & $-1,13$ & $-1,46$ & $-0,77$ & 0,30 \\
\hline Ideal Comfort ${ }^{\circledR}$ & $1 \mathrm{~mm}$ & 5 & 0,157 & $-0,90$ & $-1,24$ & $-0,62$ & 0,27 \\
\hline Ideal Comfort ${ }^{\circledR}$ & $1 \mathrm{~mm}$ & 5 & 0,360 & $-1,85$ & $-2,15$ & $-1,62$ & 0,20 \\
\hline Ideal Comfort ${ }^{\circledR}$ & $1 \mathrm{~mm}$ & 5 & $-0,360$ & $-2,07$ & $-2,44$ & $-1,59$ & 0,35 \\
\hline Ideal Comfort ${ }^{\circledR}$ & $1 \mathrm{~mm}$ & 5 & $-0,157$ & $-0,99$ & $-1,25$ & $-0,86$ & 0,17 \\
\hline
\end{tabular}

Tabelle 3.1.1: Deskriptive Statistik für die intrusiven Kräfte $(F z)$ in Newton $(N)$. Die Tabelle enthält die Anzahl der für die Messungen eingesetzten thermoplastisch geformten Schienen (n), die Mittelwerte (Mean), Maxima (Max), Minima (Min) und Standardabweichungen (SD) der gemessenen Werte für die untersuchten Materialien bei Auslenkungsstrecken von 0,157mm, $-0,157 \mathrm{~mm}, 0,360 \mathrm{~mm}$ und $-0,360 \mathrm{~mm}$. 
Die Tabelle 3.1.1 zeigt die deskriptive Statistik für die gemessenen intrusiven Kräfte (Fz) der untersuchten Materialien und Auslenkungsstrecken. Bei den aufgeführten Mittelwerten (Mean), Maxima (Max), Minima (Min) und Standardabweichungen (SD) handelt es sich um aufgerundete Werte (Tab. 3.1.1).

Im Folgenden werden die Messergebnisse der einzelnen Materialien für die intrusive Kraft (Fz) durch Box-Whisker-Plots dargestellt (Abb. 3.1.1 - 3.1.4).

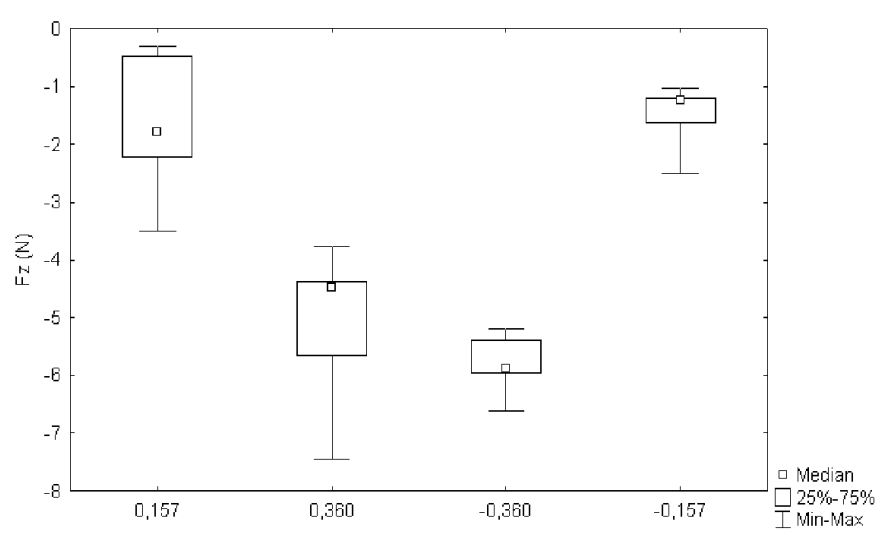

Abbildung 3.1.1: Box Plots zur Darstellung der intrusiven Kräfte (Fz) in Newton (N) für das Material Biolon ${ }^{\circledR}$ bei den Auslenkungsstrecken 0,157 mm, -0,157 mm, 0,360 mm und -0,360 mm.

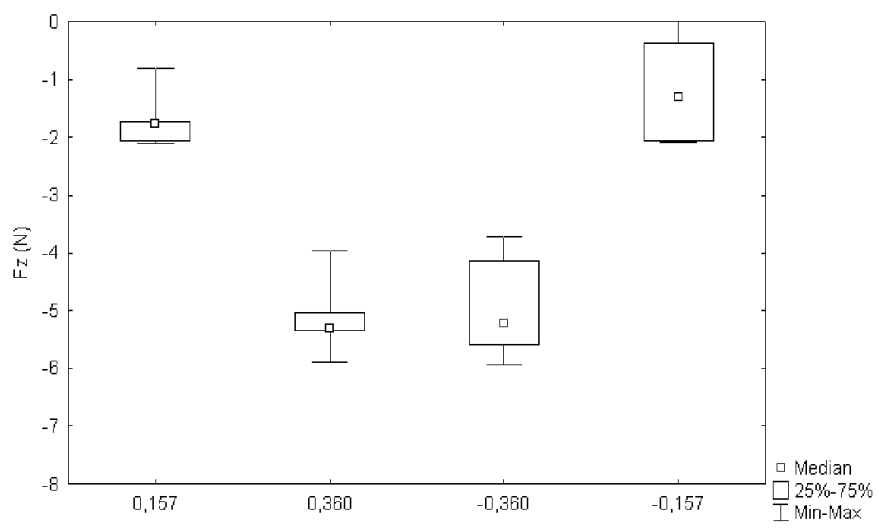

Abbildung 3.1.2: Box Plots zur Darstellung der intrusiven Kräfte (Fz) in Newton (N) für das Material Ideal Clear ${ }^{\circledR}$ bei den Auslenkungsstrecken 0,157 mm, -0,157 mm, 0,360 mm und-0,360 mm. 


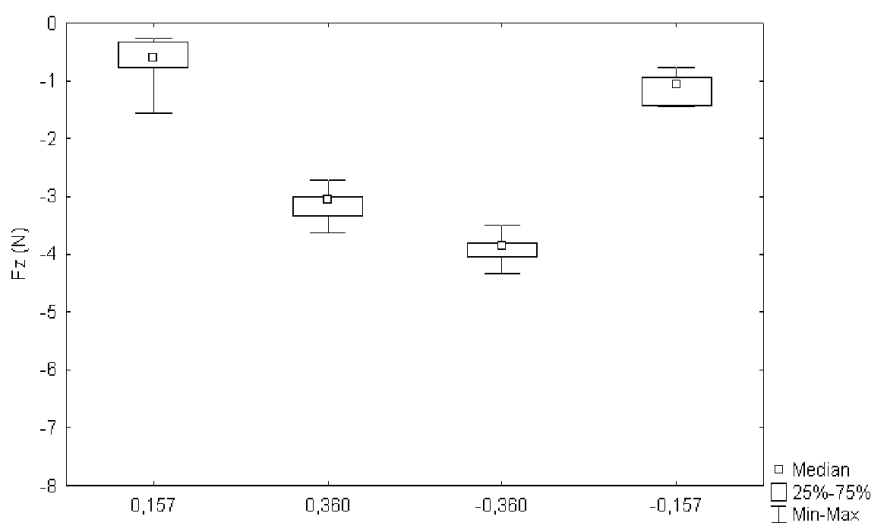

Abbildung 3.1.3: Box Plots zur Darstellung der intrusiven Kräfte (Fz) in Newton (N) für das Material Erkodur ${ }^{\circledR}$ bei den Auslenkungsstrecken 0,157 mm, -0,157 mm,0,360 mm und-0,360 mm.

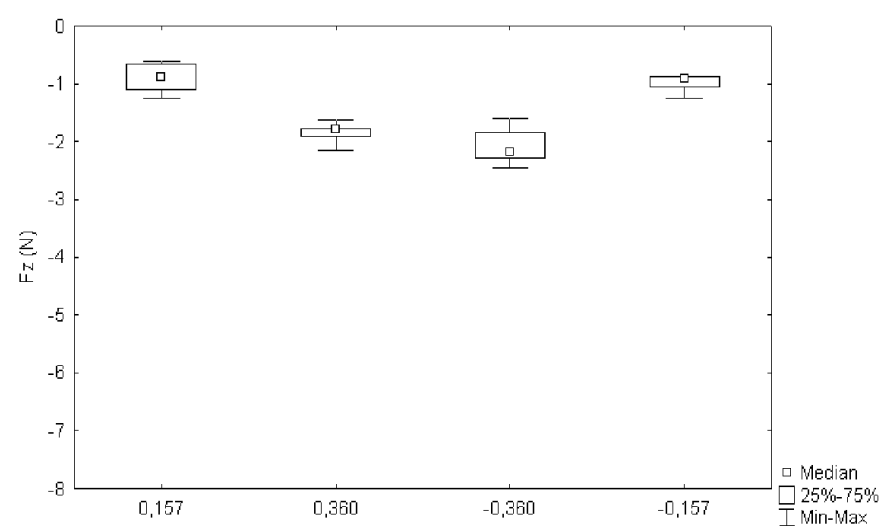

Abbildung 3.1.4: Box Plots zur Darstellung der intrusiven Kräfte (Fz) in Newton (N) für das Material Ideal Comfort $^{\circledR}$ bei den Auslenkungsstrecken 0,157 mm, -0,157 mm, 0,360 $\mathrm{mm}$ und $-0,360 \mathrm{~mm}$.

Für den niedrigen Aktivierungsbereich $(0,157 \mathrm{~mm}$ und $-0,157 \mathrm{~mm})$ sind durchschnittlich intrusive Kräfte zwischen -0,70 N (Erkodur $\left.{ }^{\circledR}\right)(\mathrm{SD} 0,52)$ und -1,69 N (Ideal Comfort $\left.{ }^{\circledR}\right)$ (SD 0,52) gemessen worden. Von Erkodur ${ }^{\circledR}$ - und Ideal Comfort ${ }^{\circledR}$-Schienen wurden im niedrigen Auslenkungsbereich maximal Kräfte von -1,56 N abgegeben. Ein höheres Niveau der Maximalwerte zeigten die Ideal Clear ${ }^{\circledR}$ - und Biolon ${ }^{\circledR}-$ Schienen, die bei $-2,09 \mathrm{~N}$ bis $-3,5 \mathrm{~N}$ lagen (vgl. Tab. 3.1.1). 
Die Durchschnittswerte für den höheren Aktivierungsbereich $(0,360 \mathrm{~mm}$ und $-0,360 \mathrm{~mm})$

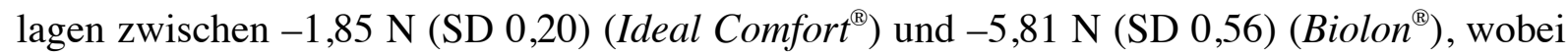
die Biolon ${ }^{\circledR}$ - und Ideal Clear ${ }^{\circledR}$-Schienen eine ähnlich hohe Kraftabgabe mit Werten von $-4,92 \mathrm{~N}$ bis $-5,81 \mathrm{~N}$ zeigten. Der Maximalwert der höheren Auslenkungsstrecken lag bei $-7,45 \mathrm{~N}\left(\right.$ Biolon $\left.^{\circledR}\right)$.

Die Messungen der Erkodur ${ }^{\circledR}$-Schienen ergaben Durchschnittswerte von -3,15 N (SD 0,35) bis $-3,91 \mathrm{~N}$ (SD 0,30). Die deutlich niedrigsten Werte erzeugten die Ideal Comfort $^{\circledR}$-Schienen mit $-2,15 \mathrm{~N}(\mathrm{SD} 0,20)$ bis $-2,44 \mathrm{~N}(\mathrm{SD} 0,35)$ und einem Minimalwert von $-1,59 \mathrm{~N}$.

Die materialabhängigen Unterschiede in der Kraftabgabe im höheren Aktivierungsbereich werden bei Betrachtung des Minimalwertes für Biolon ${ }^{\circledR}$-Schienen $(-3,76 \mathrm{~N})$ im Vergleich mit dem halb so hohen Durchschnittswert von $-1,85 \mathrm{~N}(\mathrm{SD} 0,20)$ für die Ideal Comfort $^{\circledR}$-Schienen deutlich (vgl. Tab. 3.1.1).

Bei Erhöhung der Aktivierungsstrecke des Messzahnes (von 0,157 mm auf 0,360 mm bzw. von $-0,157 \mathrm{~mm}$ auf $-0,360 \mathrm{~mm}$ ) stieg die durchschnittliche Kraftabgabe in beiden Rotationsrichtungen bei den Materialien Biolon ${ }^{\circledR}$, Ideal Clear ${ }^{\circledR}$ und Erkodur ${ }^{\circledR}$ überproportional an. Nur Ideal Comfort ${ }^{\circledR}$ wies eine Krafterhöhung um lediglich das Doppelte auf (vgl. Tab. 3.1.1).

Im folgenden Abschnitt werden die untersuchten Materialien in Bezug auf die Kraftabgabe miteinander verglichen. Deutliche, materialabhängige Unterschiede in der Kraftabgabe waren bei den höheren Auslenkungsstrecken (0,360 mm und -0,360 mm) festzustellen.

Zur Untersuchung der Abhängigkeit zwischen Auslenkungsstrecke und Material wurde eine zweifaktorielle Analyse durchgeführt. Diese zeigte, dass die Interaktion Strecke/Material signifikant ist (p-Wert <0,0001). Der Einfluss des Materials wurde statistisch mit Paarvergleichen untersucht.

Die Ergebnisse der Paarvergleiche der Auslenkungsstrecken 0,360 mm und -0,360 mm sind den Tabellen 3.1.2 und 3.1.3 zu entnehmen. Sie werden zusätzlich in den Diagrammen der Abbildungen 3.1.5 und 3.1.6 dargestellt.

Für die Auslenkungsstrecken 0,157 mm (p-Wert 0,09) und -0,157 mm (p-Wert 0,41) konnte kein signifikanter Unterschied festgestellt werden. 


\begin{tabular}{|c|c|}
\hline Vergleich & p-Wert \\
\hline Gesamt & $<0,0001$ \\
\hline Biolon $^{\circledR}$ vs. Erkodur ${ }^{\circledR}$ & 0,01 \\
\hline Biolon $^{\circledR}$ vs. Ideal Clear $^{\circledR}$ & 0,99 \\
\hline Biolon $^{\circledR}$ vs. Ideal Comfort ${ }^{\circledR}$ & $<0,0001$ \\
\hline Erkodur $^{\circledR}$ vs. Ideal Clear ${ }^{\circledR}$ & 0,0002 \\
\hline Erkodur $^{\circledR}$ vs. Ideal Comfort ${ }^{\circledR}$ & 0,001 \\
\hline 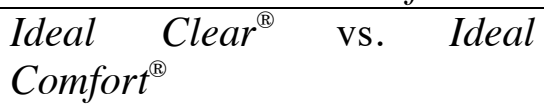 & $<0,0001$ \\
\hline
\end{tabular}

Tabelle 3.1.2: Tabellarische Darstellung der Paarvergleiche mit Angabe der p-Werte für alle gemessenen Materialien für die Auslenkungsstrecke 0,360 $\mathrm{mm}$.

Für die Auslenkungsstrecke 0,360 mm zeigten die einzelnen Paarvergleiche, dass abgesehen von dem Vergleich Biolon ${ }^{\circledR} /$ Ideal $_{\text {Clear }}{ }^{\circledR}$ alle Paarvergleiche statistisch signifikant unterschiedlich in der Kraftabgabe waren (vgl. Tab. 3.1.2 und Abb. 3.1.5).

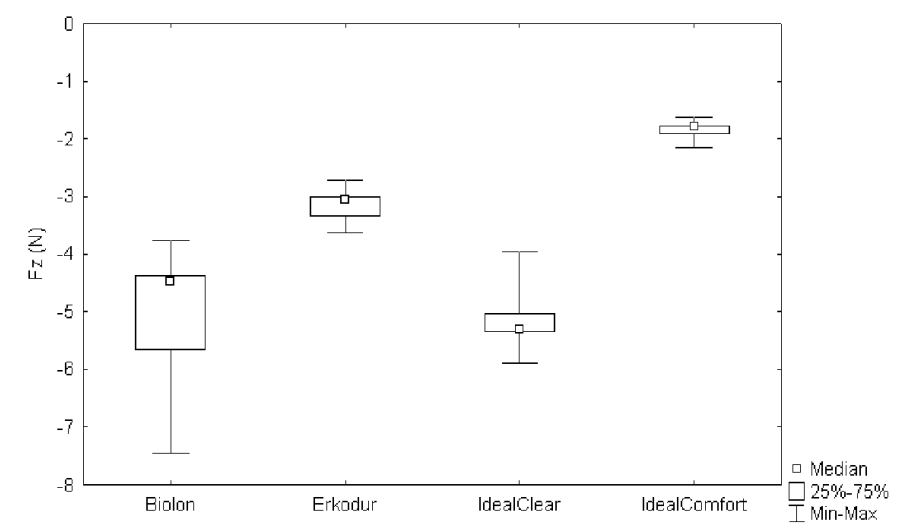

Abbildung 3.1.5: Box Plots zur Darstellung der intrusiven Kräfte (Fz) in Newton (N) für alle gemessenen Materialien bei der Auslenkungsstrecke 0,360 mm. 


\begin{tabular}{|c|c|}
\hline Vergleich & p-Wert \\
\hline Gesamt & $<0,0001$ \\
\hline Biolon $^{\circledR}$ vs. Erkodur ${ }^{\circledR}$ & 0,001 \\
\hline Biolon $^{\circledR}$ vs. Ideal Clear ${ }^{\circledR}$ & 0,43 \\
\hline Biolon $^{\circledR}$ vs. Ideal Comfort ${ }^{\circledR}$ & $<0,0001$ \\
\hline Erkodur $^{\circledR}$ vs. Ideal Clear ${ }^{\circledR}$ & 0,26 \\
\hline Erkodur $^{\circledR}$ vs. Ideal Comfort ${ }^{\circledR}$ & 0,001 \\
\hline $\begin{array}{l}\text { Ideal } \text { Clear }^{\circledR} \\
\text { Comfort }^{\circledR}\end{array}$ & 0,001 \\
\hline
\end{tabular}

Tabelle 3.1.3: Tabellarische Darstellung der Paarvergleiche mit Angabe der p-Werte für alle gemessenen Materialien für die Auslenkungsstrecke $-0,360 \mathrm{~mm}$.

Die für die Auslenkungsstrecke von $-0,360 \mathrm{~mm}$ aufgezeigte hoch signifikant unterschiedliche Kraftabgabe $(\mathrm{p}<0.0001)$ von Biolon ${ }^{\circledR}$ vs. Ideal Comfort ${ }^{\circledR}$ ist bei Betrachtung der BoxWhisker-Plots in Abbildung 3.1.6 deutlich erkennbar.

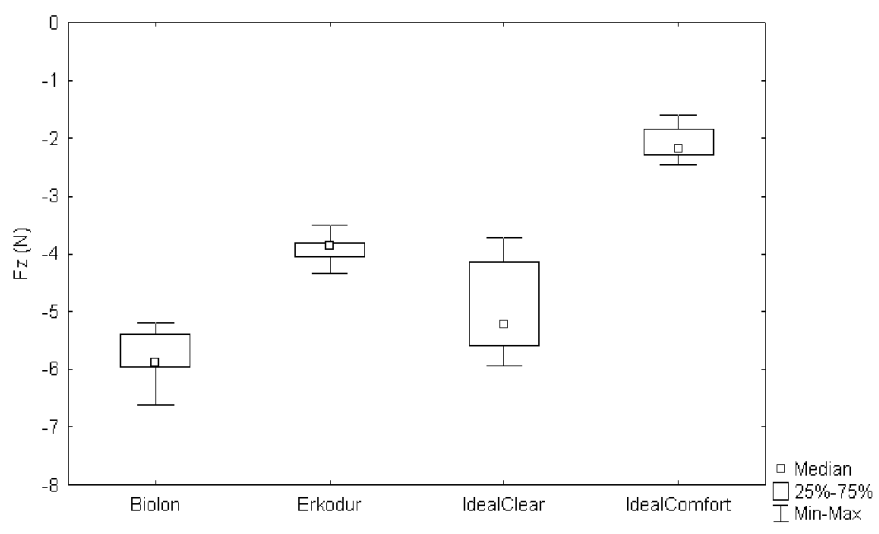

Abbildung 3.1.6: Box Plots zur Darstellung der intrusiven Kräfte (Fz) in Newton (N) für alle gemessenen Materialien bei der Auslenkungsstrecke $-0,360 \mathrm{~mm}$. 


\section{2 Ergebnisse der von thermoplastisch geformten Schienen ausgehenden rotativen}

Drehmomente (Tz)

\begin{tabular}{|c|l|l|c|c|c|c|c|}
\hline Material & Stärke & n & Strecke(mm) & Mean(Nmm) & Max(Nmm) & Min(Nmm) & SD \\
\hline Biolon $^{\circledR}$ & $1 \mathrm{~mm}$ & 5 & 0,157 & 36,57 & 44,75 & 25,95 & 8,40 \\
Biolon $^{\circledR}$ & $1 \mathrm{~mm}$ & 5 & & & & & \\
& & & 0,360 & 87,56 & 99,71 & 75,99 & 9,24 \\
Biolon $^{\circledR}$ & $1 \mathrm{~mm}$ & 5 & $-0,360$ & $-65,61$ & $-72,63$ & $-59,31$ & 5,28 \\
Biolon $^{\circledR}$ & $1 \mathrm{~mm}$ & 5 & $-0,157$ & $-19,46$ & $-27,74$ & $-15,25$ & 5,52 \\
\hline Ideal Clear $^{\circledR}$ & $1 \mathrm{~mm}$ & 5 & 0,157 & 21,60 & 29,36 & 7,82 & 8,55 \\
Ideal Clear $^{\circledR}$ & $1 \mathrm{~mm}$ & 5 & 0,360 & 48,91 & 57,36 & 35,70 & 9,30 \\
Ideal Clear $^{\circledR}$ & $1 \mathrm{~mm}$ & 5 & $-0,360$ & $-39,83$ & $-50,95$ & $-27,44$ & 10,21 \\
Ideal Clear $^{\circledR}$ & $1 \mathrm{~mm}$ & 5 & $-0,157$ & $-11,70$ & $-22,19$ & $-2,03$ & 8,80 \\
\hline Erkodur $^{\circledR}$ & $1 \mathrm{~mm}$ & 5 & 0,157 & 23,67 & 36,58 & 16,89 & 8,49 \\
Erkodur $^{\circledR}$ & $1 \mathrm{~mm}$ & 5 & 0,360 & 53,85 & 70,74 & 33,17 & 14,09 \\
Erkodur $^{\circledR}$ & $1 \mathrm{~mm}$ & 5 & $-0,360$ & $-33,70$ & $-42,84$ & $-20,54$ & 8,25 \\
Erkodur $^{\circledR}$ & $1 \mathrm{~mm}$ & 5 & $-0,157$ & $-6,90$ & $-10,96$ & $-2,33$ & 3,80 \\
\hline Ideal Comfort $^{\circledR}$ & $1 \mathrm{~mm}$ & 5 & 0,157 & 8,59 & 12,52 & 6,82 & 2,32 \\
Ideal Comfort $^{\circledR}$ & $1 \mathrm{~mm}$ & 5 & 0,360 & 16,43 & 21,57 & 13,17 & 3,43 \\
Ideal Comfort $^{\circledR}$ & $1 \mathrm{~mm}$ & 5 & $-0,360$ & $-14,22$ & $-16,75$ & $-9,67$ & 2,72 \\
Ideal Comfort $^{\circledR}$ & $1 \mathrm{~mm}$ & 5 & $-0,157$ & $-6,38$ & $-7,55$ & $-5,30$ & 0,94 \\
\hline
\end{tabular}

Tabelle 3.2.1: Deskriptive Statistik für die rotativen Drehmomente (Tz) in Newtonmillimeter (Nmm). Die Tabelle enthält die Anzahl der für die Messungen eingesetzten thermoplastisch geformten Schienen (n), die Mittelwerte (Mean), Maxima (Max), Minima (Min) und Standardabweichungen (SD) der gemessenen Werte für untersuchten Materialien bei Auslenkungsstrecken von 0,157 mm, $-0,157 \mathrm{~mm}, 0,360 \mathrm{~mm}$ und $-0,360 \mathrm{~mm}$.

Der Tabelle 3.2.1 sind die gemessenen Drehmomente (Tz) zu entnehmen. Auch hier handelt es sich um aufgerundete Werte.

Zunächst werden die Messergebnisse für die rotativen Drehmomente (Tz) der einzelnen Materialien durch Box-Whisker-Plots dargestellt (vgl. Abb. 3.2.1 - 3.2.5). 


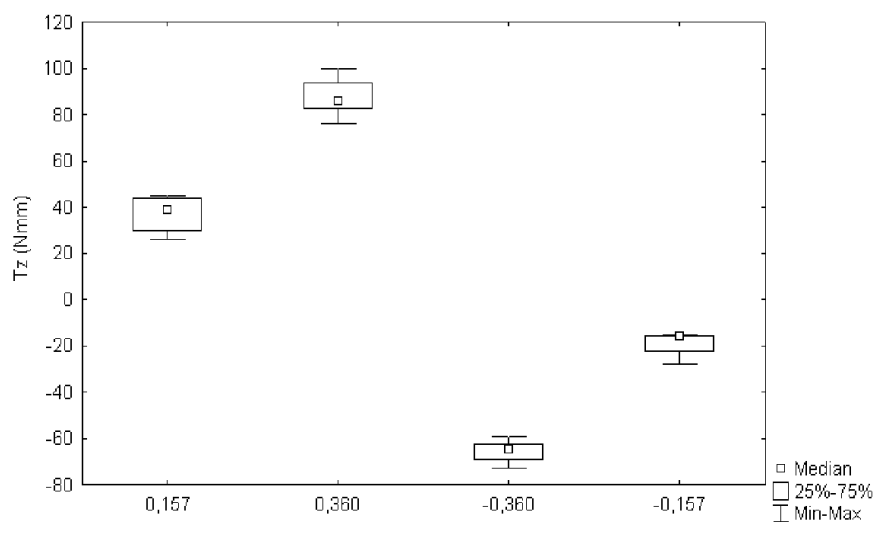

Abbildung 3.2.1: Box Plots zur Darstellung der rotativen Drehmomente (Tz) in Newtonmillimeter (Nmm) für das Material Biolon ${ }^{\circledR}$ bei den Auslenkungsstrecken 0,157 mm, $-0,157 \mathrm{~mm}, 0,360 \mathrm{~mm}$ und-0,360 $\mathrm{mm}$.

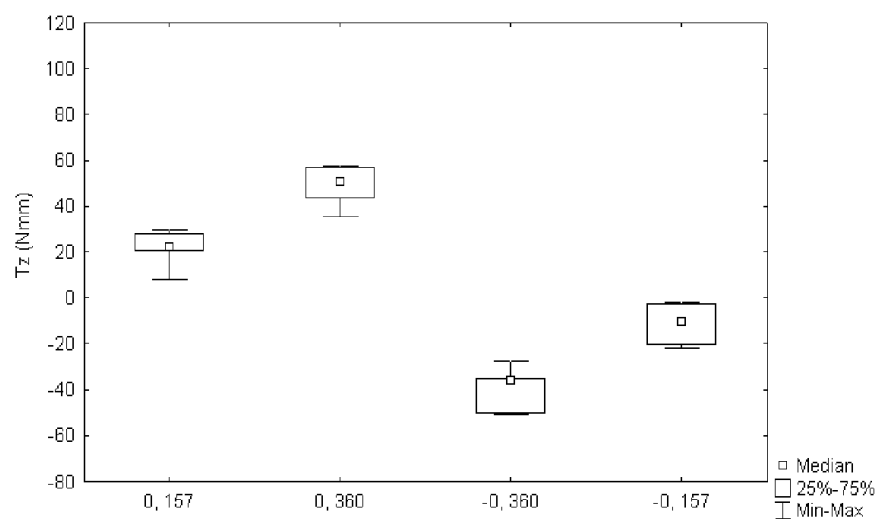

Abbildung 3.2.2: Box Plots zur Darstellung der rotativen Drehmomente (Tz) in Newtonmillimeter (Nmm) für das Material Ideal Clear ${ }^{\circledR}$ bei den Auslenkungsstrecken 0,157 mm, -0,157 mm, 0,360 mm und-0,360 mm. 


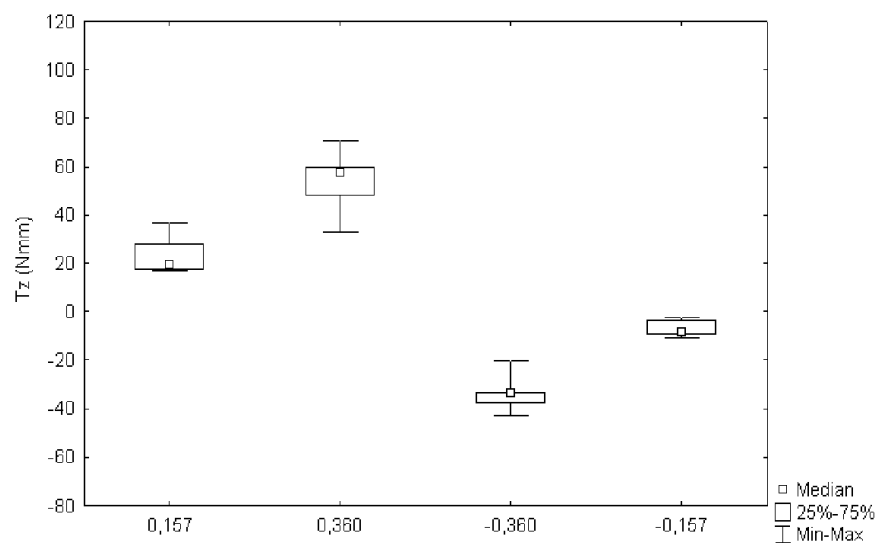

Abbildung 3.2.3: Box Plots zur Darstellung der rotativen Drehmomente (Tz) in Newtonmillimeter (Nmm) für das Material Erkodur ${ }^{\circledR}$ bei den Auslenkungsstrecken 0,157 mm, -0,157 mm, 0,360 mm und -0,360 mm.

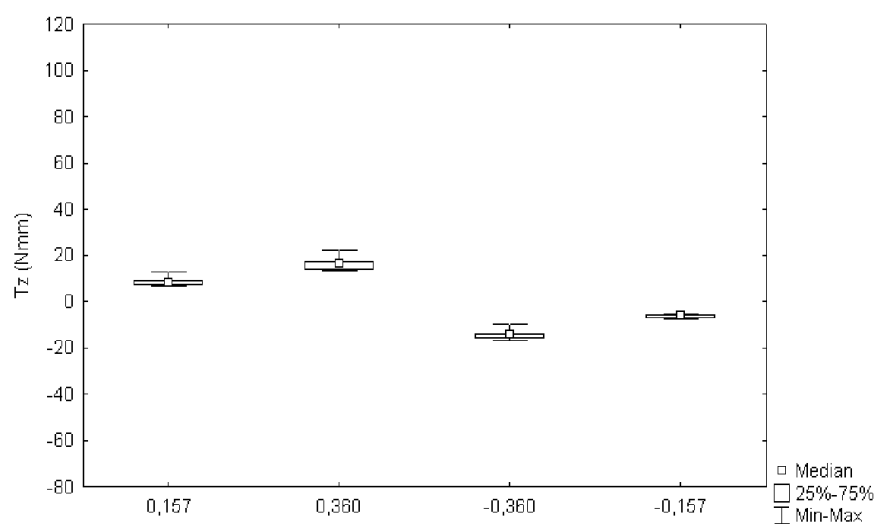

Abbildung 3.2.4: Box Plots zur Darstellung der rotativen Drehmomente (Tz) in Newtonmillimeter (Nmm) für das Material Ideal Comfort ${ }^{\circledR}$ bei den Auslenkungsstrecken 0,157 mm, -0,157 mm, 0,360 mm und-0,360 mm. 
Die Messungen der Auslenkungsstrecken $0,157 \mathrm{~mm}$ und $-0,157 \mathrm{~mm}$ ergaben Durchschnittswerte von -6,38 Nmm (SD 0,94) (Ideal Comfort ${ }^{\circledR}$ ) bis 36,57 Nmm (SD 8,40) $\left(\right.$ Biolon $\left.^{\circledR}\right)$. Maximal wurden in diesem Aktivierungsbereich 44,75 Nmm (Biolon ${ }^{\circledR}$ ) gemessen. Der Minimalwert lag bei -2,03 Nmm (Ideal Clear ${ }^{\circledR}$ ).

Im höheren Aktivierungsbereich (0,360 $\mathrm{mm}$ und $-0,360 \mathrm{~mm})$ ergaben die Messungen Werte zwischen -14,22 Nmm (SD 2,72) $\left(\right.$ Ideal Comfort $\left.^{\circledR}\right)$ und 87,56 Nmm (SD 9,24) $\left(\right.$ Biolon $\left.^{\circledR}\right)$. Der Maximalwert betrug 99,71 Nmm $\left(\right.$ Biolon $\left.^{\circledR}\right)$. Der niedrigste Wert wurde für die Ideal Comfort ${ }^{\circledR}$-Schienen gemessen $(-9,67 \mathrm{Nmm})$ (vgl. Tab. 3.2.1).

Generell wurden bei der Rotationsrichtung des Messzahnes mit dem Uhrzeigersinn $(-0,157$ $\mathrm{mm}$ und $-0,360 \mathrm{~mm}$ ) niedrigere Werte gemessen als in entgegengesetzter Rotationsrichtung. Die Materialien Biolon $^{\circledR}$, Erkodur ${ }^{\circledR}$ und Ideal Clear $^{\circledR}$ zeigten mit Erhöhung der Auslenkungsstrecke (von -0,157 mm auf -0,360 mm) einen Anstieg der Nmm-Werte um bis zu ca. 490\%. In entgegen gesetzter Drehrichtung des Zahnes (0,157 mm auf 0,360 mm) hingegen um nur ca. $230 \%$.

Für die Werte für $\mathrm{Tz}$ zeigte die zweifaktorielle Analyse, dass die Interaktion Auslenkungsstrecke/Material für alle Aktivierungsstrecken $(0,157 \mathrm{~mm},-0,157 \mathrm{~mm}, 0,360$ $\mathrm{mm}$ und $-0,360 \mathrm{~mm})$ signifikant unterschiedlich ist $(\mathrm{p}$-Wert $<0,0001)$. Die einzelnen Paarvergleiche werden im Folgenden in Tabellen vorgestellt und durch Box-Whisker-Plots in Abbildungen visualisiert (vgl. Tab. 3.2.2 - 3.2.5 und Abb. 3.2.5 - 3.2.8). 


\begin{tabular}{|l|r|}
\hline Vergleich & p-Wert \\
\hline Gesamt & $<0,0001$ \\
\hline & \\
\hline Biolon $^{\circledR}$ vs. Erkodur & \\
\hline Biolon $^{\circledR}$ vs. Ideal Clear & 0,08 \\
\hline Biolon $^{\circledR}$ vs. Ideal Comfort & 0,08 \\
\hline Erkodur $^{\circledR}$ vs. Ideal Clear $^{\circledR}$ & $<0,0001$ \\
\hline Erkodur $^{\circledR}$ vs. Ideal Comfort & 1 \\
\hline Ideal Clear $^{\circledR}$ vs. Ideal Comfort & \\
\hline
\end{tabular}

Tabelle 3.2.2: Tabellarische Darstellung der Paarvergleiche mit Angabe der p-Werte für alle gemessenen Materialien für die Auslenkungsstrecke 0,157 mm.

Für die Auslenkungsstrecke 0,157 mm sind für die Paarvergleiche Biolon ${ }^{\circledR} /$ Ideal Comfort $^{\circledR}$, Erkodur $^{\circledR} /$ Ideal Comfort $^{\circledR}$ und Ideal Clear $^{\circledR} /$ Ideal $^{\text {Comfort }}{ }^{\circledR}$ statistisch signifikante Unterschiede in der Drehmomentabgabe gezeigt worden (vgl. Abb. 3.2.5).

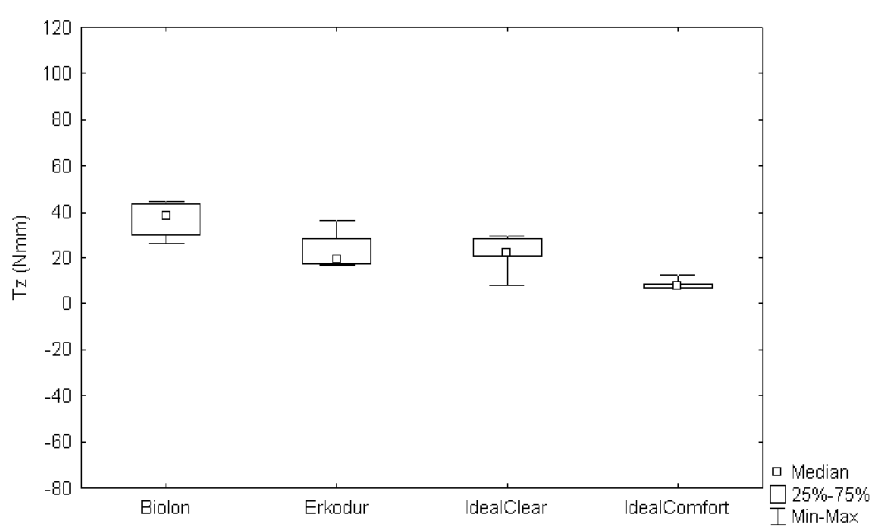

Abbildung 3.2.5: Box Plots zur Darstellung der rotativen Drehmomente (Tz) in Newtonmillimeter (Nmm) für alle gemessenen Materialien bei der Auslenkungsstrecke 0,157 mm. 


\begin{tabular}{|l|r|}
\hline Vergleich & p-Wert \\
\hline Gesamt & 0,01 \\
\hline & \\
\hline Biolon $^{\circledR}$ vs. Erkodur & 0,01 \\
\hline Biolon $^{\circledR}$ vs. Ideal Clear & 0,35 \\
\hline Biolon $^{\circledR}$ vs. Ideal Comfort & $<0,0001$ \\
\hline Erkodur $^{\circledR}$ vs. Ideal Clear $^{\circledR}$ & 0,88 \\
\hline Erkodur $^{\circledR}$ vs. Ideal Comfort $^{\circledR}$ & 0,99 \\
\hline${\text { Ideal } \text { Clear }^{\circledR} \text { vs. Ideal Comfort }}^{\circledR}$ & 0,74 \\
\hline
\end{tabular}

Tabelle 3.2.3: Tabellarische Darstellung der Paarvergleiche mit Angabe der p-Werte für alle gemessenen Materialien für die Auslenkungsstrecke -0,157 mm.

Bei der Auslenkungsstrecke $-0,157$ mm wurde nur für die Paarvergleiche Biolon ${ }^{\circledR}$ vs. Ideal Comfort $^{\circledR}$ und Biolon ${ }^{\circledR}$ vs. Erkodur ${ }^{\circledR}$ eine Signifikanz in der Drehmomentabgabe gezeigt (vgl. auch Abb. 3.2.6).

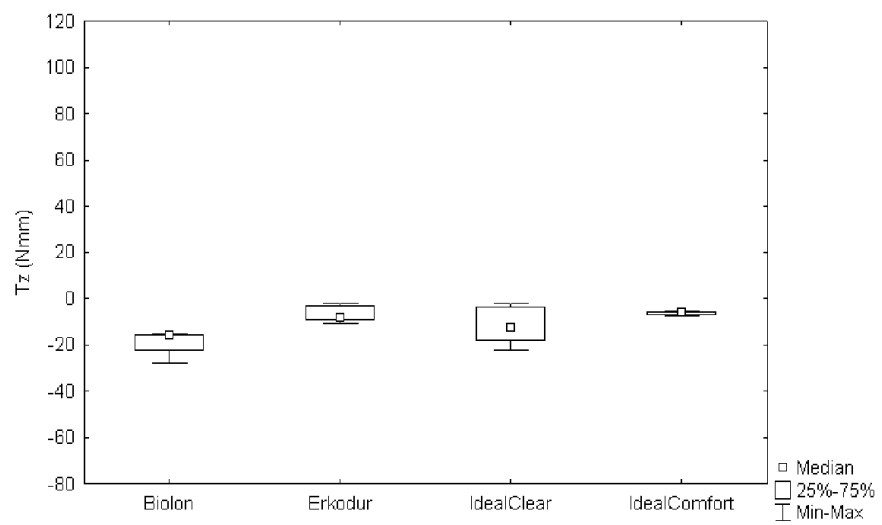

Abbildung 3.2.6: Box Plots zur Darstellung der rotativen Drehmomente(Tz) in Newtonmillimeter (Nmm) für alle gemessenen Materialien bei der Auslenkungsstrecke -0,157 mm. 


\begin{tabular}{|l|r|}
\hline Vergleich & p-Wert \\
\hline Gesamt & $<0,0001$ \\
\hline & \\
\hline Biolon $^{\circledR}$ vs. Erkodur & 0,01 \\
\hline Biolon $^{\circledR}$ vs. Ideal Clear $^{\circledR}$ & $<0,0001$ \\
\hline Biolon $^{\circledR}$ vs. Ideal Comfort & $<0,0001$ \\
\hline Erkodur $^{\circledR}$ vs. Ideal Clear & 0,79 \\
\hline Erkodur $^{\circledR}$ vs. Ideal Comfort & 0,002 \\
\hline${\text { Ideal } \text { Clear }^{\circledR}}^{\circledR}$ vs. Ideal Comfort & 0,0002 \\
\hline
\end{tabular}

Tabelle 3.2.4: Tabellarische Darstellung der Paarvergleiche mit Angabe der p-Werte für alle gemessenen Materialien für die Auslenkungsstrecke 0,360 mm.

Der Tabelle 3.2.4 ist zu entnehmen, dass für die Auslenkungsstrecke 0,360 mm, abgesehen von dem Vergleich Erkodur ${ }^{\circledR} /$ Ideal $_{\text {Clear }}^{\circledR}$, alle Paarvergleiche eine statistische Signifikanz aufwiesen (vgl. auch Abb. 3.2.7).

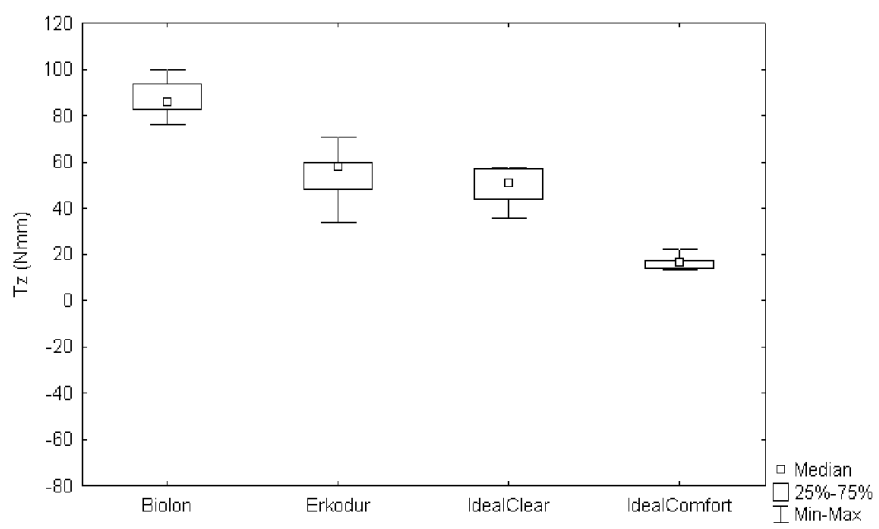

Abbildung 3.2.7: Box Plots zur Darstellung der rotativen Drehmomente (Tz) in Newtonmillimeter (Nmm) für alle gemessenen Materialien bei der Auslenkungsstrecke 0,360 mm. 


\begin{tabular}{|l|r|}
\hline Vergleich & p-Wert \\
\hline gesamt & $<0,0001$ \\
\hline & \\
\hline Biolon $^{\circledR}$ vs. Erkodur & \\
\hline Biolon $^{\circledR}$ vs. Ideal Clear $^{\circledR}$ & 0,0002 \\
\hline Biolon $^{\circledR}$ vs. Ideal Comfort & 0,004 \\
\hline Erkodur $^{\circledR}$ vs. Ideal Clear & $<0,0001$ \\
\hline Erkodur $^{\circledR}$ vs. Ideal Comfort & 0,79 \\
\hline Ideal Clear $^{\circledR}$ vs. Ideal Comfort $^{\circledR}$ & 0,002 \\
\hline
\end{tabular}

Tabelle 3.2.5: Tabellarische Darstellung der Paarvergleiche mit Angabe der p-Werte für alle gemessenen Materialien für die Auslenkungsstrecke $-0,360 \mathrm{~mm}$.

Die Darstellung durch die Box Plots in Abbildung 3.2.8. für die Auslenkungsstrecke $-0,360$ mm machen den Unterschied in der Drehmomentabgabe für die Materialien Biolon ${ }^{\circledR}$ vs. Ideal Comfort $^{\circledR}$ deutlich. Der visuelle Eindruck wird durch den statistischen Paarvergleich mit einem p-Wert von kleiner als 0,0001 bestätigt (vgl. Tab. 3.2.5).

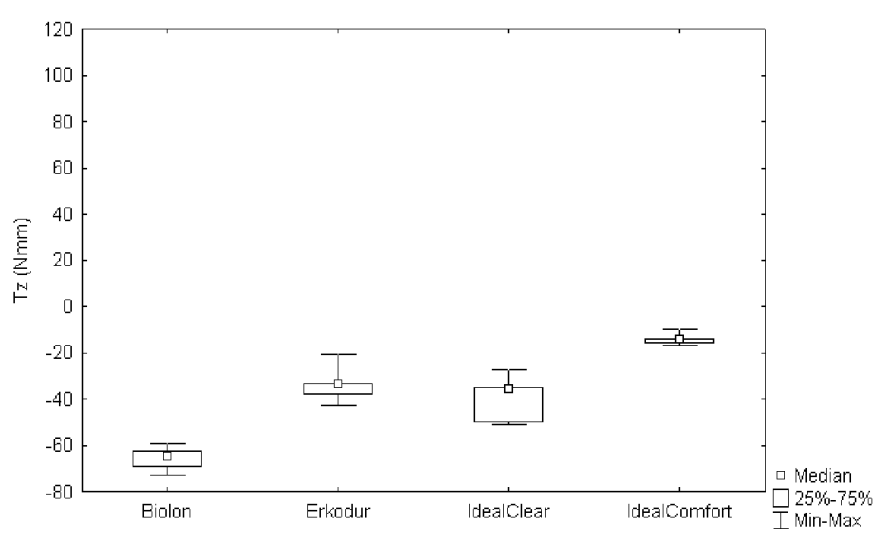

Abbildung 3.2.8: Box Plots zur Darstellung der rotativen Drehmomente (Tz) in Newtonmillimeter (Nmm) aller gemessenen Materialien für die Auslenkungsstrecke $-0,360 \mathrm{~mm}$. 


\section{Diskussion}

Obwohl Aligner schon seit den 1940er Jahren zur Behandlung von Zahnfehlstellungen eingesetzt werden (Kesling 1945, Nahoum 1964, Ponitz 1971, McNamara et al. 1985, Lindauer und Shoff 1998), existieren bisher nur wenige Untersuchungen, die sich mit der Biomechanik der thermoplastisch geformten Schienen befassen (Kwon et al 2008, Warunek et al. 1989, Rost et al. 1995, Barbagallo et al. 2008a). Die vorliegende Arbeit ist Teil einer Studienserie, in der eine systematische Untersuchung der von Schienen applizierten Kräfte und Drehmomente umgesetzt wurde. Für die biomechanischen Messungen ist eine neu entwickelte In-vitro-Messapparatur eingesetzt worden, mit der es erstmals gelungen ist, die von thermoplastisch geformten Schienen ausgehenden vertikalen und horizontalen Kräfte und die Drehmomente getrennt voneinander zu messen.

Im Zentrum dieser Arbeit stehen die Ergebnisse der Messungen für die intrusive Kraft $(\mathrm{Fz})$ und das rotative Drehmoment $(\mathrm{Tz})$, die bei der Rotation eines unteren seitlichen Schneidezahnes (42) von thermoplastisch geformten Schienen ausgehen. Von besonderem Interesse waren der Einfluss der Auslenkungsstrecke $(0,157 \mathrm{~mm}$ und 0,360 mm in beiden Rotationsrichtungen des Messzahnes) und der verschiedenen Schienenmaterialien (Biolon ${ }^{\circledR}$, Erkodur $^{\circledR}$, Ideal Clear ${ }^{\circledR}$, Ideal Comfort ${ }^{\circledR}$ ) auf die generierten Kräfte und Drehmomente.

\subsection{Entstehung der intrusiven Kraft (Fz) bei der Rotation eines Unterkieferfrontzahnes um seine Längsachse}

Bevor die oben genannte Studienserie zur Erforschung der von Alignern ausgehenden Kräfte und Drehmomente durchgeführt wurde (Hahn 2009, Hahn et al. 2009a, Hahn et al. 2009b, Hahn et al. 2010a, Hahn et al. 2010b, Hahn et al. 2011, Engelke 2010, Seiffert 2012, ErfurthJach 2012), stand die Frage im Raum, ob neben den für die Rotation notwendigen horizontal wirkenden Kräften auch eine messbare vertikale Kraftkomponente bei der Rotationsbewegung eines Schneidezahnes mit Alignern auftritt. Für das Rotieren um die Längsachse eines Frontzahnes tragen vertikale Kräfte nicht zur gewünschten Zahnbewegung bei, so dass auftretende intrusive Kräfte in diesem Zusammenhang als Nebeneffekt bezeichnet werden können. Hahn et al. bewiesen bereits, dass Aligner relevante intrusive Kräfte bei der Rotation eines oberen Inzisivus generieren (Hahn et al. 2010a, 2011).

Mit den Ergebnissen der vorliegenden Arbeit konnte gezeigt werden, dass auch bei der Rotation eines unteren Frontzahnes intrusive Kräfte erzeugt werden. 
Brezniak (2008) beschrieb das Auftreten von unerwünschten Intrusionen bei der Schienenbehandlung. Die erstmals als universelles Phänomen beschriebenen intrusiven Kräfte bei der Schienentherapie (Hahn 2009, Hahn et al. 2009a, 2009b, 2010a, 2010b, 2011, Engelke 2010, Seiffert 2012) und auch die Ergebnisse der vorliegenden Arbeit können diese Beobachtung erklären.

Auf welche Weise intrudierende Kräfte theoretisch erzeugt werden, wird im Folgenden beschrieben. Der für die Derotation eines Frontzahnes eingesetzte Aligner entspricht in seiner Form bereits der gewünschten Zahnstellung, da die Position des zu bewegenden Zahnes vor dem Tiefziehvorgang auf dem Gipsmodell verändert wurde. Die Form des Aligners unterscheidet sich dementsprechend von der aktuellen Zahnposition. Durch die daraus resultierende Inkongruenz zwischen Schienenform und reeller Zahnposition kommt es zu verschiedenen Kontaktbereichen zwischen Schiene und Zahn, die einen Widerstand erzeugen. Daraus resultiert eine lokale Verformung der Schiene im Bereich des Messzahnes, die zu intrusiv wirkenden Rückstellkräften führt: Bei Betrachtung eines seitlichen Unterkieferschneidezahnes von inzisal hat die Schneidekante des Zahnes zunächst im mesiolingualen und distolabialen Bereich Kontakt zu der geneigten Innenfläche der Schiene. Die dabei entstehende Kraft (F) wird an Flächen erzeugt, die schräg zur Längsachse stehen. Diese lässt sich in eine horizontale Kraftkomponente $(\mathrm{Fx})$ und eine vertikale Kraftkomponente (Fz) zerlegen (Hahn 2009) (vgl. Abb. 4.1).

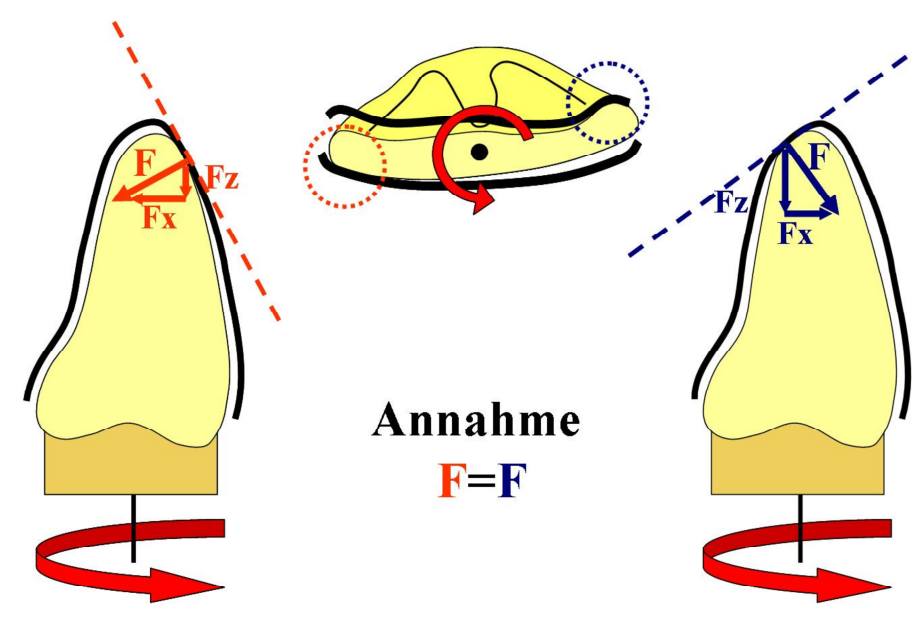

Abbildung 4.1: Bei der Rotation des unteren seitlichen Frontzahnes (42) gegen den Uhrzeigersinn entstehen distolabial und mesiolingual Kontakte zwischen Zahn und Schieneninnenfläche. Die schräg zur Längsachse des Zahnes ansetzende Kraft $F$ lässt sich in eine horizontale Kraftkomponente (Fx) und eine vertikale Kraftkomponente $(\mathrm{Fz})$ zerlegen (Hahn 2009). 
Während der Messungen wurde beobachtet, dass sich die Schiene im Bereich des Messzahnes durch die vorhandene Inkongruenz zwischen Schienenform und reeller Zahnposition in Abhängigkeit vom Ausmaß der Auslenkungsstrecke von dem Messzahn abhebt. Da die gesamte Schiene durch Friktionskräfte im Seitenzahnbereich gehalten wird, verformt sich zusätzlich zu der lokalen Verformung der gesamte Schienenkörper, was wiederum zu Rückstellkräften führt, die ebenfalls auf den zu bewegenden Zahn einwirken. Diese auf zwei unterschiedliche Arten erzeugten Rückstellkräfte wirken, wie oben beschrieben, als intrusive Kräfte auf den Messzahn (Hahn 2009).

Es ist jedoch anzunehmen, dass die Entstehung intrusiver Kräfte bei der Rotation eines natürlichen Unterkieferfrontzahnes mit Alignern wesentlich diffiziler ist, als oben beschrieben. Die Kontaktbereiche zwischen Aligner und Zahn ändern sich mit einsetzender Zahnbewegung fortlaufend, so dass, je nach aktueller Position des Zahnes, Kräfte an unterschiedlich stark geneigten Oberflächen erzeugt werden. Daraus resultiert eine Vielzahl an Vektorkombinationen, die schwer vorhersagbar ist (Hahn 2009). Die einzelnen Auswirkungen der erzeugten Vektoren auf die Zahnbewegung konnten mit der vorliegenden Untersuchung nicht nachvollzogen werden, da eine reine Rotationsbewegung durch die starre Verbindung zwischen Messzahn und Sensor vorgegeben war. Eine reine Rotationsbewegung ist theoretisch nur möglich, wenn ein Kräftepaar zwei gleich großer parallel verlaufender Kräfte mit gegenläufigem Kraftansatz erzeugt wird (Smith und Burstone 1984). Es ist aber unwahrscheinlich, dass dieses Kräftepaar unter natürlichen Umständen in jeder Phase der Rotationsbewegung erzeugt wird, da mit der Rotation des Zahnes stetig neue Kontaktbereiche zwischen Schiene und Zahn und dadurch andere Kombinationen von auf den Zahn einwirkenden Vektoren an unterschiedlich stark geneigten Flächen des Zahnes gebildet werden.

Daraus kann man schließen, dass eine reine Rotationsbewegung eines unteren Frontzahnes mit Schienen in einem natürlichen biologischen Umfeld nahezu auszuschließen ist. Eher ist von einer Rotationsbewegung auszugehen, die mit anderen Zahnbewegungsformen kombiniert auftritt.

Für ein tiefer gehendes Verständnis sind biomechanische In-vivo-Untersuchungen erforderlich.

\subsection{Diskussion der Messergebnisse für die intrusive Kraft (Fz)}

Die ersten Untersuchungen zu einer geeigneten Kraftgröße zur Bewegung eines Zahnes wurden in den 1870er Jahren durchgeführt (Farrar 1876). 
Nachdem zuerst dafür plädiert wurde, unabhängig von der Effizienz der Zahnbewegung möglichst schwache Kräfte für eine schonende orthodontische Zahnbewegung anzuwenden (Farrar 1876, Schwarz 1932, Oppenheim 1942, Reitan 1967), ist man heute der Ansicht, dass sowohl biologische Aspekte als auch die Zahnbewegungseffizienz als Kriterien für eine optimale Kraft berücksichtigt werden müssen (Ren et al. 2003). Eine ideale orthodontische Kraft, im Sinne einer daraus resultierenden effizienten Zahnbewegung ohne pathologische Nebenwirkungen, ist bisher jedoch noch nicht definiert worden (Ren et al. 2003). Als Anhaltspunkte für anzuwendende orthodontische Kräfte dienen lediglich Empfehlungen, die als Referenz zur Einschätzung der hier gemessenen intrusiven Kräfte herangezogen werden. Die Werte der vorliegenden Arbeit beliefen sich auf durchschnittlich -0,7 N (SD 0,52) bis $-1,69 \mathrm{~N}$ (SD 0,52) bei einer Auslenkungsstrecke von 0,157 mm bzw. $-0,157 \mathrm{~mm}$ und auf $-1,85 \mathrm{~N}(\mathrm{SD} 0,2)$ bis $-5,81 \mathrm{~N}(\mathrm{SD} 0,56)$ bei einer Auslenkungsstrecke von 0,360 mm bzw. $-0,360 \mathrm{~mm}$.

Schopf (2000) empfiehlt unterschiedlich hohe Kräfte für den Beginn und für die fortgeschrittene kieferorthopädische Therapie.

Mit dem Einsatz schonender Kräfte $\left(0,2-0,3 \mathrm{~N} / \mathrm{cm}^{2}\right)$ zu Beginn der Behandlung soll die Blutversorgung des Parodontiums erhalten bleiben, um Zellnekrosen zu vermeiden. Während der Phase der Eliminierung der Nekrosezonen steigt das Risiko für Schäden an der Wurzel und ist zu Beginn der Behandlung höher (Diedrich 1990, Schopf 2000). Schopf setzt die Kraft außerdem in Relation zu der Wurzeloberfläche des zu bewegenden Zahnes. Je größer die Wurzeloberfläche ist, desto eher werden höhere Kräfte toleriert (Göz 2000). Bezogen auf eine durchschnittlich 1,7 $\mathrm{cm}^{2}$ große Wurzeloberfläche eines seitlichen Unterkieferschneidezahnes (Jepsen 1963), der in der vorliegenden Arbeit untersucht wurde, wären nach Schopf (2000) Kräfte zwischen 0,35 $\mathrm{N}$ und 0,5 $\mathrm{N}$ für den Behandlungsbeginn und 1,7 $\mathrm{N}$ bis 3,5 $\mathrm{N}$ in der späteren Behandlungsphase akzeptabel. Die hier gewonnenen Messwerte für die intrusive Kraft (Fz) zeigten, dass die von Schopf empfohlenen Werte für den Behandlungsbeginn schon bei niedriger Auslenkungsstrecke $(0,157 \mathrm{~mm}$ bzw. $-0,157 \mathrm{~mm})$ überschritten werden. Der niedrigste Mittelwert von $-0,70 \mathrm{~N}(\mathrm{SD} 0,52)$ wurde für Erkodur ${ }^{\circledR}$-Schienen gemessen. Auch die im Stadium der fortgeschrittenen Behandlung empfohlenen Werte sind teilweise deutlich übertroffen worden. Biolon ${ }^{\circledR}$ - und Ideal Clear ${ }^{\circledR}$-Schienen generierten bei der höheren Auslenkungsstrecke intrusive Kräfte, die aufgerundet $1,5 \mathrm{~N}$ bis 2,5 $\mathrm{N}$ höher waren, als die maximal empfohlenen 3,5 N (Biolon ${ }^{\circledR}-5,81 \mathrm{~N}(\mathrm{SD} 0,56)$ und Ideal Clear ${ }^{\circledR}-4,92 \mathrm{~N}$ (SD 0,95)). Für Ideal Comfort ${ }^{\circledR}$-Schienen wurden hingegen insgesamt relativ niedrige Werte 
gemessen, die unterhalb des Grenzwertes von 3,5 N lagen (Ideal Comfort $^{\circledR}-1,85 \mathrm{~N}$ (SD 0,20) bzw. -2,07 N (SD 0,35)).

Kritisch anzumerken ist, dass Schopf seine Angaben für anzuwendende orthodontische Kräfte im Gegensatz zu anderen Autoren (Proffit 2000, Diedrich 1990, Faltin et al. 1998) nicht auf die unterschiedlichen Zahnbewegungsformen bezieht. Die angestrebte Zahnbewegung sollte aber ein Kriterium für die anzuwendende Kraft darstellen (Nicholls et al. 1974). Denn für eine horizontale Zahnbewegung ist die in horizontaler Richtung zu betrachtende Wurzeloberfläche eines Zahnes größer und dadurch belastbarer, als die von apikal zu betrachtende wesentlich kleinere Wurzeloberfläche, die bei einer intrusiven Zahnbewegung belastet wird.

Der Vergleich der hier erfassten Messwerte mit den von Schopf empfohlenen Werten hat aus diesem Grund nur eine eingeschränkte Aussagekraft.

Proffit (2000) gibt einen Maximalwert von 1,25 N für die Rotationsbewegung als ideale Kraft an. Für die kleinere Auslenkungsstrecke lagen nur die Werte für Biolon ${ }^{\circledR}$ - und Ideal Clear ${ }^{\circledR}$ Schienen über den empfohlenen 1,25 N. Bis zu 4,6fach höhere Werte als die von Proffit angegebenen 1,25 N wurden für die größere Auslenkungsstrecke $(0,360 \mathrm{~mm}$ bzw. $-0,360 \mathrm{~mm})$ gemessen. Wird eine Intrusion als korrektive Maßnahme angestrebt, sollten die intrusiven Kräfte $0,1 \mathrm{~N}$ bis $0,3 \mathrm{~N}$ nicht überschreiten, da besonders durch die Intrusion mit zu hohen Kräften Nebenwirkungen, wie Wurzelresorptionen, hervorgerufen werden können (Diedrich 1990). Die in der vorliegenden Arbeit gemessenen intrusiven Kräfte, die als Nebeneffekt bei der Rotationsbewegung auftraten, lagen bei allen untersuchten Materialien oberhalb des von Proffit empfohlenen Bereiches. Schon bei der niedrigeren Auslenkungsstrecke entstanden durchschnittlich intrusive Kräfte, die aufgerundet bis zu sechs mal höher waren als $0,3 \mathrm{~N} \quad\left(-1,69 \mathrm{~N} \quad\left(\mathrm{SD}\right.\right.$ 0,52) für Ideal Clear $\left.^{\circledR}\right)$. Bei einer Auslenkungsstrecke von $0,360 \mathrm{~mm}$ bzw. $-0,360 \mathrm{~mm}$ wurden sechs- bis neunzehnfach höhere Kräfte (Fz) gemessen $\left(-1,85 \mathrm{~N}\right.$, SD 0,20 für Ideal Comfort ${ }^{\circledR}$ und $-5,81 \mathrm{~N}$, SD 0,56 für Biolon $^{\circledR}$ ).

Zusammenfassend können die in der vorliegenden Untersuchung gemessenen intrusiven Kräfte, mit Ausnahme einiger Werte für die kleinere Auslenkungsstrecke und für das Material Ideal Comfort ${ }^{\circledR}$, als zu hoch bezeichnet werden. Zu große Kräfte erhöhen das Risiko für Nebenwirkungen wie Hyalinisation, Stagnation der Zahnbewegung und Wurzelresorptionen bei der orthodontischen Zahnbewegung (Beck und Harris 1994, Levander und Malmgreen 1988, Sameshima und Sinclair 2001, Alhashmimi et al. 2001, Hartsfield et al. 2004, 
Barbagallo et al. 2008b, Casa et al. 2001, Faltin et al. 1998, Harris et al. 2006, Dermaut und De Munck 1986, McFadden et al. 1989, Schopf 2000, Reitan 1951, Reitan 1960, Schwarz 1932, Rygh 1973).

Theoretisch könnten auch die vergleichsweise $\mathrm{zu}$ hohen Kräfte, die bei den Auslenkungsstrecken von 0,157 mm bzw. $-0,157 \mathrm{~mm}$ erzeugt wurden, eingesetzt werden, ohne dass mit einem erhöhten Risiko für Wurzelresorptionen zu rechnen wäre, da die Auslenkungsstrecke in diesem Fall kleiner ist als die durchschnittliche Parodontalspaltbreite (Coolidge 1937) (vgl. Abschnitt 4.4). Weiterhin muss für die Beurteilung der zu hohen Kräfte, die in der vorliegenden Arbeit gemessen wurden, beachtet werden, dass diese den zu bewegenden Zahn nur in der ersten Phase, nach dem Einsetzen der Schiene, belasten. Denn die Konstruktion der Messapparatur erlaubte keine aus dem Kraftansatz resultierende Zahnbewegung, so dass nur die initialen Kräfte gemessen werden konnten. Initiale Kräfte wirken auf den Zahn, bevor dieser sich in einem natürlichen Zahnhalteapparat in die von der Schiene vorgegebenen Richtung bewegen würde. Die Kräfte nehmen mit einsetzender Zahnbewegung ab, da der Zahn sich von der Kraftquelle, deren Kraftgröße von der Auslenkungsstrecke abhängig ist, entfernt (Barbagallo et al. 2008a).

Wie die Studie von Barbagallo et al. (2008a) mit einer In-vivo-Messmethode zeigt, ist nach der durch die Schienenkraft bedingten Zahnbewegung ein deutlicher Kraftabfall zu verzeichnen. Das Prinzip des In-vivo-Messverfahrens beruht darauf, dass bei Druckapplikation durch einen Aligner ein Farbstoff in den verwendeten Pressurex ${ }^{\circledR}$ Filmen produziert wird. Die Pressurex ${ }^{\circledR}$ Filme befinden sich zwischen der Schiene und dem zu bewegenden Zahn. Die je nach Druck unterschiedlich stark ausgeprägte Farbproduktion erlaubt einen Rückschluss auf die Kraft, indem die sich verändernde optische Dichte gemessen bzw. mit Filmen verglichen wird, die einem bekannten Druckausmaß ausgesetzt waren. Die Ergebnisse von Barbagallo et al. (2008a) zeigten für die initiale Kraft einen Wert von durchschnittlich 5,12 N. Der Durchschnittswert für die Kraft, die nach einsetzender Zahnbewegung gemessen wurde, lag bei 1,12 N. Dieses Untersuchungsergebnis lässt vermuten, dass die initialen Kräfte weitaus höher sind als die Kräfte, die erzeugt werden, nachdem die Zahnbewegung initiiert wurde. Im Gegensatz zu der vorliegenden Untersuchung konnten Barbagallo et al. (2008a) jedoch die einzelnen Kraftkomponenten nicht getrennt voneinander messen, was die Aussagekraft der Ergebnisse begrenzt.

Der Nachteil einer In-vitro-Messmethode hingegen ist der Verzicht auf die Simulation eines natürlichen parodontalen Ligaments. Das parodontale Ligament zeigt ein viskoelastisches Verhalten. Im Zusammenhang mit der Applikation einer Kraft sind die Hysterese, die 
Zunahme der Steifigkeit des Parodontalligaments bei zunehmender Belastungsgeschwindigkeit und die Abhängigkeit von der Belastungsgeschichte von besonderer Bedeutung (Dorow et al. 2002, 2003). Bisher ist es nicht gelungen das viskoelastische Verhalten des parodontalen Ligaments mithilfe einer Messapparatur zu imitieren, so dass auch in der Studienserie von Hahn (Hahn 2009, Hahn et al. 2009a, 2009b, 2010a, 2010 b, 2011, Engelke 2010, Seiffert 2012) darauf verzichtet werden musste.

Bis heute stellt das Messen initialer Kräfte eine weit verbreitete Messmethode dar, da immer noch vornehmlich Messapparaturen mit starren Verbindungen zwischen Messzahn und Sensor eingesetzt werden (Baccetti et. al. 2008, Bartzela et al. 2007, Lim et al. 2008, Pandis et al. 2008a und 2008b, Walker et al. 2007, Wang et al. 2007).

Um genauere Kenntnisse über den oben erwähnten Kraftabfall nach einsetzender Zahnbewegung zu erlangen, und um die Auswirkungen zu hoher Kräfte in den verschiedenen Phasen der Krafteinwirkung zu verstehen, wären klinische und biomechanische Untersuchungen in vivo und in vitro wünschenswert. Die in dieser Arbeit gewonnenen Messwerte könnten in diesem Zusammenhang als valide Vergleichswerte dienen.

\subsection{Diskussion der Messergebnisse für das Drehmoment (Tz)}

Die in dieser Untersuchung eingesetzte Messapparatur ermöglicht das differenzierte Messen der einzelnen Kraft- und Drehmomentkomponenten. Neben den Ergebnissen für die vertikale Kraftkomponente liegt der Fokus dieser Arbeit auch auf den Messwerten für die Drehmomente, die bei der Rotation des Messzahnes von Alignern erzeugt wurden. Zur Beurteilung der gewonnenen Werte für die erzeugten Drehmomente werden diese mit Werten verglichen, die in der Literatur als ideale Drehmomente angegeben sind.

Bei gesunden parodontalen Verhältnissen werden $5 \mathrm{Nmm}$ bis $15 \mathrm{Nmm}$ empfohlen (Diedrich 1990). Melsen und Burstone (1990) hingegen geben $30 \mathrm{Nmm}$ als maximales Drehmoment für die Rotation an. Unterhalb des von Diedrich angegebenen Akzeptanzbereiches lagen für die höhere Auslenkungsstrecke nur die Werte, die für Ideal Comfort $^{\circledR}$-Schienen in der Rotationsrichtung des Messzahnes mit dem Uhrzeigersinn $(-0,360 \mathrm{~mm})$ gemessen wurden. Alle anderen Messwerte für die höhere Auslenkungsstrecke (0,360 mm bzw. - 0,360 mm) lagen bis zu 72,56 Nmm über den angegebenen $15 \mathrm{Nmm}$. Die Werte für die niedrigere Auslenkungsstrecke in Rotationsrichtung des Messzahnes mit dem Uhrzeigersinn $(-0,157 \mathrm{~mm})$ lagen abgesehen von dem Messwert für Biolon ${ }^{\circledR}-$ Schienen $(-19,46 \mathrm{Nmm}$, SD 
5,52) unter $15 \mathrm{Nmm}$. In entgegengesetzter Rotationsrichtung des Messzahnes wurden durchschnittlich höhere Werte von bis zu 36,57 Nmm $\left(\right.$ Biolon $\left.^{\circledR}\right)(\mathrm{SD} 8,40)$ gemessen.

Der zweite Vergleichswert von $30 \mathrm{Nmm}$ (Melsen und Burstone 1990) bezieht sich ausschließlich auf die Rotationsbewegung von Molaren. Dieser Wert kann deshalb nur als sinnvoller Vergleichswert herangezogen werden, wenn er entsprechend dem Verhältnis zwischen Drehmoment und Wurzeloberfläche umgerechnet wird. Bei anzustrebenden $30 \mathrm{Nmm}$ für eine Wurzeloberfläche von Molaren mit durchschnittlich $5,3 \mathrm{~cm}^{2}$, wären umgerechnet 9,6 Nmm für eine Wurzeloberfläche von durchschnittlich 1,7 $\mathrm{cm}^{2}$ von unteren seitlichen Schneidezähnen anzuwenden (Lehmann und Hellwig 2002).

Für die größere Auslenkungsstrecke wurden in der vorliegenden Untersuchung ausschließlich höhere Werte als 9,6 Nmm gemessen. Nur Erkodur ${ }^{\circledR}$ - und Ideal Comfort $^{\circledR}$-Schienen applizierten bei der geringeren Auslenkungsstrecke Drehmomente, die kleiner als 9,6 Nmm waren.

Abgesehen von den Messwerten für die Ideal Comfort $^{\circledR}$-Schienen sind in der Gesamtbetrachtung der Messwerte für das rotative Drehmoment $(\mathrm{Tz})$ vergleichsweise zu hohe Werte gemessen worden. In der Beurteilung sind jedoch dieselben Anmerkungen zur Konstruktion der Messapparatur zu berücksichtigen, die schon für die Messwerte der intrusiven Kraft aufgeführt wurden. Mit der in der vorliegenden Arbeit eingesetzten Messapparatur wurden ausschließlich die initialen Drehmomente gemessen, die der oben beschriebenen These nach höher sind, als die nach initiierter Zahnbewegung wirkende Kräfte und Drehmomente. Da das Ausmaß von orthodontisch induzierten Wurzelresorptionen von der angewandten Kraftgröße abhängt (Faltin et al. 1998), könnte davon ausgegangen werden, dass das Risiko für biologische Nebenwirkungen mit einsetzender Zahnbewegung sinkt.

Die Untersuchung von Wurzelresorptionen während der Schienentherapie war nicht Gegenstand der vorliegenden Arbeit. Dennoch sollen die aktuellsten Erkenntnisse zu diesem Thema nicht unerwähnt bleiben, da Wurzelresorptionen eine der am häufigsten beobachteten Komplikationen kieferorthopädischer Behandlungen sind. Sie treten bei $57 \%$ der Patienten auf. Das Ausmaß einer Wurzelresorption steigt im Allgemeinen mit zunehmender Kraft, wobei die intrusive Kraft die Gefahr von Wurzelresorptionen im Besonderen erhöht (Beck und Harris 1994, Casa et al. 2001, Faltin et al.1998, Harris et al. 2006, Levander und Malmgreen 1988, McFadden et al. 1989, Remington et al. 1989, Sameshima und Sinclair 2001, Alhashmimi et al. 2001, Hartsfield et al. 2004, Barbagallo et al. 2008b, Dermaut und De Munck 1986). Besonders anfällig für Resorptionen sind die Wurzeln der Ober- und 
Unterkieferschneidezähne (Apajalathi und Peltola 2007, Brezniak und Wasserstein 2008), die in der Studienserie von Hahn (Hahn 2009, Hahn et al. 2009a, 2009b, 2010a, 2010b, 2011, Engelke 2010, Seiffert 2012, Erfurth-Jach 2012), zu der die vorliegende Arbeit auch gehört, untersucht wurden.

Die Ergebnisse dieser Arbeit präsentierten initiale intrusive Kräfte und Drehmomente, die die in der Literatur als ideal angegebenen Werte zum Teil um ein Mehrfaches überschreiten, so dass theoretisch von schädigenden Nebenwirkungen ausgegangen werden muss. Inwiefern die Behandlung mit thermoplastisch geformten Schienen zu Wurzelresorptionen führt, wurde bisher aber nicht eindeutig geklärt. Einige Studien zeigen, dass bei orthodontischen Schienenbehandlungen nur vergleichsweise geringe Wurzelresorptionen zu beobachten waren (Barbagallo et al. 2008b, Boyd 2008, Brezniak und Wasserstein 2008). Bisher wird dieses Phänomen mit der Herausnehmbarkeit der Schienen erklärt (Linge und Linge 1983, 1991).

Diese Erklärung beruht auf der Annahme, dass herausnehmbare Apparaturen durch die Unterbrechung der Kraftapplikation eine Heilung des resorbierten Zementes im Bereich der Wurzeln der belasteten Zähne erlauben (Dougherty 1968, Reitan 1964, Oppenheim 1930, Oppenheim 1942, Levander und Malmgren 1994, Maltha und Dijkman 1996, Acar et al. 1999, Weiland 2003). Vermutlich sinkt die Gefahr einer Wurzelresorption, je länger die Phase der ausbleibenden Kraftapplikation ist (Acar et al. 1999, Maltha und Dijkman 1996). In der Schienentherapie wird die Empfehlung ausgesprochen die Aligner nahezu ununterbrochen zu tragen, um ein adäquates Behandlungsergebnis zu erzielen (Bollen et al. 2003, Vlaskalic et al. 2001). Das würde bedeuten, dass besonders bei Patienten mit einer hohen Compliance ein höheres Risiko für Wurzelresorptionen zu erwarten wäre.

Ein anderer Erklärungsansatz für geringere Wurzelresorptionen während der Schienentherapie könnte das oben erwähnte Anheben der Schiene während der Zahnbewegung sein. Wird die Schiene nicht vollständig auf den Zähnen gehalten, kann das Ausmaß der ursprünglich eingestellten Auslenkungsstrecke nicht vollständig wirken. Infolgedessen werden geringere Kräfte auf die zu bewegenden Zähne appliziert, so dass von einem niedrigeren Risiko für Wurzelresorptionen auszugehen ist. Das Anheben der Schiene könnte in diesem Zusammenhang als ein immanenter Schutzmechanismus bezeichnet werden (Hahn 2009).

Hinsichtlich der Ergebnisse für die Drehmomente (Tz) war neben den durchschnittlich zu hohen Werten außerdem bemerkenswert, dass deutlich niedrigere Werte für die Rotationsrichtung des Messzahnes mit dem Uhrzeigersinn (-0,157 und $-0,360 \mathrm{~mm})$ gemessen 
wurden, als für die Drehmomente gegen den Uhrzeigersinn $(0,157$ und 0,360 mm). Diese Unterschiede dürften auf der Reihenfolge der Messungen beruhen: Bei jedem Messzyklus wurden die Messungen für die intrusive Kraft (Fz) und das Drehmoment (Tz) zunächst für die Rotationsrichtung des Messzahnes gegen den Uhrzeigersinn und anschließend für die Drehrichtung mit dem Uhrzeigersinn durchgeführt. Jede Schiene durchlief einen Messzyklus, in dem der Messzahn in $0,5^{\circ}$ Schritten von $0^{\circ}$ auf $10^{\circ}$ (gegen den Uhrzeigersinn) und zurück auf $0^{\circ}$ rotiert wurde, danach von $0^{\circ}$ auf $-10^{\circ}$ (mit dem Uhrzeigersinn) und wieder auf $0^{\circ}$. Während der ersten Hälfte der Messungen (gegen den Uhrzeigersinn) nimmt der zwischen der Schiene und dem Messzahn erzeugte Widerstand mit Erhöhung der Auslenkungsstrecke zu. Dadurch kommt es vermutlich zu einer Dehnung des Schienenmaterials. Diese könnte sich in einer nachlassenden Präzision der Schienenpassform äußern. Die folgenden Messungen für die Rotationsrichtung des Messzahnes mit dem Uhrzeigersinn wurden demzufolge mit Schienen durchgeführt, die zuvor mechanisch belastet wurden und eine geringere Passgenauigkeit im Bereich des Messzahnes aufwiesen. Die weniger exakte Passform könnte zu geringeren Rückstellkräften und dadurch zu niedrigeren Drehmomenten führen.

Als Gegenargument für diese Annahme muss jedoch berücksichtigt werden, dass eine Schiene während der unterschiedlichen Drehrichtungen an unterschiedlichen Stellen belastet wird, da sich die Kontaktpunkte zwischen Schiene und Zahn je nach Rotationsrichtung ändern. Bei Betrachtung eines unteren Schneidezahnes von inzisal hat der Zahn in der Rotationsrichtung gegen den Uhrzeigersinn zunächst distolabial und mesiolingual Kontakt mit der inneren Oberfläche der Schiene. Im Gegensatz dazu kommt es in entgegengesetzter Rotationsrichtung zuerst zu Kontakten im distolingualen und mesiolabialen Bereich. Die Belastung der Schiene dürfte folglich bei der Drehrichtung des Messzahnes gegen den Uhrzeigersinn keinen Einfluss auf die erzeugte Kraft haben, die bei der Drehrichtung des Messzahnes mit dem Uhrzeigersinn erzeugt wurde, da in dem ersten Messzyklus theoretisch nur die jeweils gegenüberliegenden Stellen der Schiene gedehnt wurden.

Die oben aufgestellte These verfolgend könnte die beschriebene Beobachtung aber trotzdem die Vermutung zulassen, dass während der Messzyklen eine gewisse Materialermüdung stattgefunden hat, die zu geringeren Kräften führt. Diese Vermutung unterstützend zeigt eine Studie, dass Aligner, die über einen längeren Zeitraum einer mechanischen Belastung durch einen um $3^{\circ}$ rotierten oberen Schneidezahn ausgesetzt waren, statistisch signifikant niedrigere Kräfte und Drehmomente erzeugen, als solche, die die Kraft- und Drehmomentmessungen ohne vorherige Beanspruchungen durchliefen (Engelke 2010). Allerdings wurden in der Untersuchung von Engelke (2010) zusätzlich zu der mechanischen Beanspruchung Aspekte 
des Mundhöhlenmilieus berücksichtigt, die ebenfalls an der Entstehung niedrigerer Kräfte und Drehmomente beteiligt sein könnten. Das orale Milieu imitierend wurden die Schienen einer thermischen Wechsellast und einer 14tägigen Lagerung in $37{ }^{\circ} \mathrm{C}$ warmem Wasser ausgesetzt, so dass die Frage offen bleibt, welcher der Faktoren den wesentlichen Einfluss auf die Kraftund Drehmomentabgabe hatte, oder ob vor allem das Zusammenspiel der verschiedenen Faktoren die Kraftabgabe beeinflusste.

Es muss außerdem berücksichtigt werden, dass der Messzahn in der vorliegenden Untersuchung für jeden Messzyklus einer Schiene in kleinen Schritten bis zu einem Auslenkungswinkel von $10^{\circ}$ rotiert wurde, was einer Auslenkungsstrecke von $0,449 \mathrm{~mm}$ entspricht. Die Schienen wurden also in einem relativ kurzen Zeitraum einer zunehmenden mechanischen Belastung ausgesetzt. In der orthodontischen Behandlung hingegen ist die mechanische Belastung direkt nach dem Eingliedern einer neuen Schiene am höchsten und nimmt mit einsetzender Zahnbewegung ab.

Die vorliegende Untersuchung gibt zwar Hinweise darauf, dass sich eine mechanische Beanspruchung der Schienen auf die applizierten Drehmomente auswirkt. Aufgrund der unterschiedlichen Voraussetzungen kann die beschriebene Beobachtung aber noch nicht auf Situationen im Praxisalltag übertragen werden. Um diesen Zusammenhang zu belegen, sind weitere Untersuchungen erforderlich.

Weiterhin ist für eine Erklärung unterschiedlich hoher Messwerte für Tz in Abhängigkeit von der Rotationsrichtung des Messzahnes die Zahnmorphologie zu berücksichtigen (Engelke 2010). Die Zahnkrone eines Schneidezahnes ist, von fazial betrachtet, asymmetrisch. Der distale Winkel der vestibulären Kronenfläche, der von der Inzisalkante und der Approximalfläche der Krone gebildet wird, ist im Vergleich $\mathrm{zu}$ dem mesialen Winkel abgerundet. Dieses charakteristische Merkmal von Schneidezähnen wird als Winkelmerkmal bezeichnet (Lehmann und Hellwig 2002). Zudem unterscheidet sich die leicht nach labial gewölbte Fazialfläche von der eher schaufelförmigen Lingualfläche der klinischen Krone. Auf der lingualen Kronenfläche sind außerdem zwei schwach ausgebildete Randleisten zu finden. Diese asymmetrisch angeordneten morphologischen Merkmale der Zahnform werden während des Herstellungsprozesses der thermoplastisch geformten Schienen zunächst auf das Gipsmodell und anschließend auf den Aligner übertragen. Daraus resultieren asymmetrisch angeordnete Kontaktpunkte auf der Vestibulär- und Lingualfläche des Messzahnes, die dazu führen könnten, dass abhängig von der Rotationsrichtung des Zahnes unterschiedlich hohe Drehmomente erzeugt werden. 
Der anatomischen Zahnform entsprechend weist eine thermoplastisch geformte Schiene eine komplexe geometrische Form auf. In Bereichen starker Knickung, wie im Bereich der Inzisalkante kommt es zu einer höheren Materialsteifigkeit, die zu größeren Kräften führt, als in weniger gekrümmten Bereichen (Hahn 2009). Es ist anzunehmen, dass der Messzahn aufgrund der oben beschriebenen Asymmetrie, die auf die Schiene übertragen wird, je nach Rotationsrichtung Kontakt mit unterschiedlich stark versteiften Schienenbereichen hat. Dieser Effekt könnte ebenfalls als Erklärung für die unterschiedlich hohe Kraftabgabe in Abhängigkeit von der Rotationsrichtung des Messzahnes herangezogen werden.

Für den klinischen Praxisalltag würde das bedeuten, dass sich theoretisch auch die von Mensch zu Mensch unterschiedliche Zahnform auf die erzeugten Drehmomente ausüben könnte, was eine genaue Vorhersage einer durch Schienen applizierten Kraft deutlich erschweren würde.

In der Studienserie, zu der auch die vorliegende Studie gehört, sind zahlreiche Untersuchungen der von Schienen applizierten Kräfte und Drehmomente durchgeführt worden. Die Untersuchung von $\mathrm{Tz}$ wurde auch für die Rotationsbewegung eines Oberkieferschneidezahnes vorgenommen (Engelke 2010). Da mit Ausnahme von Ideal Comfort $^{\circledR}$ die gleichen Schienenmaterialien $\left(\right.$ Biolon $^{\circledR}$, Erkodur $^{\circledR}$, Ideal Clear $^{\circledR}$, je $1 \mathrm{~mm}$ ) bei ähnlich großer Auslenkungsstrecke $(0,34 \mathrm{~mm})$ untersucht wurden, ist ein Vergleich der Messwerte mit den Ergebnissen der vorliegenden Arbeit sinnvoll. Auffällig ist, dass bei der Untersuchung des Oberkieferschneidezahnes vergleichsweise niedrige Werte für Tz gemessen wurden $(26,7 \mathrm{Nmm}(\mathrm{SD} 1,3)$ bis 44,5 Nmm (SD 1,7)). Für die oben genannten Materialien $\left(\right.$ Biolon $^{\circledR}$, Erkodur $^{\circledR}$, Ideal Clear $\left.^{\circledR}\right)$ wurden in der vorliegenden Studie bei Auslenkungsstrecken von 0,360 mm und $-0,360 \mathrm{~mm}-33,70 \mathrm{Nmm}(\mathrm{SD} 8,25)\left(\right.$ Erkodur $\left.^{\circledR}\right)$ bis 87,56 Nmm $(\mathrm{SD} 9,24)\left(\right.$ Biolon $\left.^{\circledR}\right)$ gemessen.

Diese Beobachtung könnte mit der von Kwon et al. (2008) beschriebenen Ausdünnung der Schienen während des Herstellungsverfahrens erklärt werden, die einen signifikanten Einfluss auf die generierten Kräfte und Drehmomente hat (Kwon et al. 2008).

Vor dem Herstellungsprozess werden die Schienenrohlinge erwärmt. Nur der durch die Erwärmung erzeugte plastische Zustand des Materials erlaubt den Tiefziehvorgang der Schienen. In erwärmtem Zustand sind die Schienenrohlinge dehnbar. Umfasst das Material in dehnbarem Zustand eine größere Fläche, könnte in der Phase, in der das Material über das Gipsmodell tiefgezogen wird, eine stärkere Dehnung stattfinden, die mit einer stärkeren 
Ausdünnung der Schienen einhergeht. Da die Fläche der klinischen Krone eines Oberkieferschneidezahnes durchschnittlich signifikant größer ist, als die Fläche eines Unterkieferschneidezahnes (Lehmann und Hellwig 2002), und sowohl in der angesprochenen Untersuchung von Engelke (2010) als auch in der vorliegenden Arbeit idealisierte Schneidezähne mit verhältnismäßig angepassten Oberflächen der Kronen verwendet wurden, könnten die Aligner für die Messungen mit einem Oberkieferfrontzahn durch die stärkere Dehnung dünner sein. Je dünner das Schienenmaterial ist, umso niedriger sind die applizierten Kräfte und Drehmomente (Kwon et al. 2008, Engelke 2010).

Die Übertragung dieses Zusammenhanges auf klinische Situationen würde bedeuten, dass individuell unterschiedliche Zahngrößen mit der Erzeugung unterschiedlich hoher Kräfte und Drehmomente einhergingen. Die Einschätzung applizierter Kräfte würde dadurch noch diffiziler. Auch hier sind weitere klinische Untersuchungen erforderlich.

\subsection{Einfluss der Auslenkungsstrecke auf applizierte Kräfte und Drehmomente in der}

\section{Schienentherapie}

Neben den eingesetzten Kräften und Drehmomenten spielt die Auslenkungsstrecke, das heißt die Strecke, über die die eingesetzte Kraft wirkt, eine entscheidende Rolle in der orthodontischen Therapie: Je größer die Auslenkungsstrecke ist, desto höher ist die Krafteinwirkung auf den Zahn (Kwon et al. 2008). Ist die Auslenkungsstrecke aber kleiner als die Breite des Parodontalspaltes, könnten schädigende Einflüsse durch eine orthodontische Kraft theoretisch ausgeschlossen werden, da in dieser Situation das Parodont nicht vollständig komprimiert und die Blutzirkulation dadurch nicht unterbrochen wird (Coolidge 1937). Die Parodontalspaltbreite beträgt im Alter von 11 bis 50 Jahren durchschnittlich $0,14 \mathrm{~mm}$ bis 0,23 mm (Coolidge 1937).

In der Fachliteratur sind unterschiedliche Angaben für eine angemessene Auslenkungsstrecke zu finden. Sie variieren zwischen 0,15 mm und $1 \mathrm{~mm}$. In den 1990er Jahren wurde davon ausgegangen, dass eine Auslenkungsstrecke von $0,5 \mathrm{~mm}$ bis $1 \mathrm{~mm}$ für orthodontische Zahnbewegungen mit thermoplastisch geformten Schienen ideal sei (Sheridan et al. 1994). Später wurde für wesentlich niedrigere Auslenkungsstrecken von $0,2 \mathrm{~mm}$ bis maximal 0,5 mm plädiert (Kwon et al. 2008, Boyd et al. 2000). Faltin et al. (2003) bewegten Zähne mit thermoplastisch geformten Schienen in $0,15 \mathrm{~mm}$ bis $0,25 \mathrm{~mm}$ Schritten.

In der vorliegenden Untersuchung wurden die Kräfte $(\mathrm{Fz})$ und Drehmomente $(\mathrm{Tz})$ bei Auslenkungsstrecken von $0,157 \mathrm{~mm}$ bzw. $-0,157 \mathrm{~mm}$ und $0,360 \mathrm{~mm}$ bzw. $-0,360$ ermittelt. Der kleinere Wert lehnt sich an den niedrigsten in der Literatur angegebenen Wert von 
0,15 $\mathrm{mm}$ an (Faltin et al. 2003), dem ein Vergleichswert von 0,360 mm gegenübersteht, was abgerundet einer Verdoppelung entspricht.

Orientiert man sich an dem oben erwähnten empfohlenen Grenzwert von maximal 0,3 N für intrudierende Kräfte (Diedrich 1990), zeigten die vorliegenden Ergebnisse, dass schon bei einer Auslenkungsstrecke von 0,157 mm deutlich zu hohe intrusive Kräfte erzeugt wurden. Die Messwerte für die Drehmomente waren im Vergleich zu dem empfohlenen niedrigeren Wert von 9,6 Nmm (Melsen und Burstone 1990) bei einer Auslenkungsstrecke von 0,157 mm für die Materialien Biolon ${ }^{\circledR}$ und Ideal Clear $^{\circledR}$ zu hoch. Gegen den Uhrzeigersinn $(0,157 \mathrm{~mm})$ wurde ein höherer Durchschnittswert für Erkodur ${ }^{\circledR}$ gemessen, mit dem Uhrzeigersinn $(-0,157 \mathrm{~mm})$ lag der Wert unter 9,6 Nmm. Ideal Comfort ${ }^{\circledR}$ gab ebenfalls Werte unterhalb dieses Richtwertes ab. Theoretisch könnten die Kräfte in Bezug auf die Nebenwirkungen vernachlässigt werden, da die Auslenkungsstrecke von 0,157 mm in der Parodontalspaltbreite liegt. Die Parodontalspaltbreite ist jedoch von verschiedenen Faktoren abhängig. Sie ist interindividuell unterschiedlich, verändert sich mit zunehmendem Alter und der Funktion des Zahnes. Außerdem variiert sie je nach Lokalisation entlang der Wurzel (Coolidge 1937). Diese Variationen der Parodontalspaltbreite sind in Bezug auf die eingestellte Auslenkungsstrecke irrelevant, da es sich um Unterschiede von bis zu 0,08 mm handelt.

In Bezug auf die Auslenkungsstrecken zeigten die Messergebnisse weiterhin, dass sowohl die intrusive Kraft (Fz) als auch das Drehmoment (Tz) bei Erhöhung der Auslenkungsstrecke von $0,157 \mathrm{~mm}$ auf $0,360 \mathrm{~mm}$ bzw. von $-0,157 \mathrm{~mm}$ auf $-0,360 \mathrm{~mm}$ in allen Fällen $(100 \%)$ zunahmen. Auffallend war, dass sich die Durchschnittswerte zumindest verdoppelten, zu 75\% für Fz und zu 50\% für Tz wurde eine überproportionale Steigerung für die Durchschnittswerte festgestellt. Eine überproportionale Steigerung wurde für Fz und Tz immer für Biolon ${ }^{\circledR}$ und in keinem Fall für Ideal Comfort ${ }^{\circledR}$ errechnet.

Die zur Zahnbewegung eingesetzte Kraft in der Schienentherapie wird über die eingestellte Auslenkungsstrecke bestimmt. Eine eindeutige Aussage zu dem Verhältnis zwischen eingestellter Auslenkungsstrecke und resultierender Kraft ist anhand der vorliegenden Ergebnisse kaum möglich. Das bereits beschriebene Anheben der Schiene im Bereich des Messzahnes führt dazu, dass das ursprünglich eingestellte Ausmaß der Auslenkungsstrecke nicht vollständig wirken konnte. Die ursprünglich eingestellte Auslenkungsstrecke kann im Munde des Patienten nur umgesetzt werden, wenn die Schiene perfekt an dem zu bewegenden Zahn anliegt, da die Hauptkräfte zur Rotation des Zahnes im Bereich der Schneidekante ansetzen. Hebt die Schiene sich von dem Zahn ab, ist die tatsächlich wirkende 
Auslenkungsstrecke nicht abzuschätzen. Dass trotzdem von guten Ergebnissen bei der Frontzahnrotation berichtet wurde (Kravitz et al. 2008), könnte damit erklärt werden, dass Schluckkräfte okklusale Kräfte von bis zu 48 N erzeugen. Sie wirken durchschnittlich 40 bis 60 Mal pro Stunde mit einer Schluckdauer von jeweils 1,4 Sekunden auf die Zähne (Eichner 1963, Proffit et al. 1983, Dos Santos und de Rijk 1993, Witt und Timper 1974). Auf diese Weise wird die Schiene impulsartig auf die Zahnreihe in die vorgesehene Position gedrückt (Engelke 2010).

\subsection{Einfluss der Materialeigenschaften auf generierte Kräfte und Drehmomente}

Bisher ist keine systematische Untersuchung veröffentlicht worden, die die von unterschiedlichen Schienenmaterialien applizierten Kräfte und Drehmomente vergleichend gegenüberstellt. In der Studienserie von Hahn (Hahn 2009, Hahn et al. 2009a, 2009b, 2010a, 2010b, 2011, Engelke 2010, Seiffert 2012, Erfurth-Jach 2012), zu der die vorliegende Arbeit auch gehört, wurde erstmals die Kraftabgabe unterschiedlicher Schienenmaterialien untersucht. In einigen Untersuchungen der Studienserie wurde wiederholt festgestellt, dass Biolon ${ }^{\circledR}$ im Vergleich zu Ideal Clear ${ }^{\circledR}$ und Erkodur ${ }^{\circledR}$ bei gleicher Schienenstärke die höchsten Kräfte generiert (Hahn 2009, Hahn et al. 2009a, 2009b, 2010b, Seiffert 2012).

In der vorliegenden Arbeit wurde die Kraft- und die Drehmomentabgabe der Materialien Biolon $^{\circledR}$, Erkodur $^{\circledR}$, Ideal Clear $^{\circledR}$ und Ideal Comfort $^{\circledR}$ mit einer Dicke von jeweils einem Millimeter verglichen und statistisch untersucht. Die Messergebnisse bestätigten die oben erwähnten Ergebnisse von Hahn (2009), Hahn et al. (2009 a, 2009b, 2010b) und Seiffert (2012) und zeigten, dass Biolon ${ }^{\circledR}$ die höchsten intrusiven Kräfte und rotativen Drehmomente erzeugte. Mit abnehmenden Werten folgten für die intrusive Kraft Ideal Clear ${ }^{\circledR}$, Erkodur $^{\circledR}$ und Ideal Comfort ${ }^{\circledR}$. Ideal Comfort ${ }^{\circledR}$ generierte bei der höheren Auslenkungsstrecke immer statistisch signifikant niedrigere Werte für $\mathrm{Fz}$ und $\mathrm{Tz}$. Für $\mathrm{Tz}$ sind ähnlich hohe Werte für Ideal Clear $^{\circledR}$ und Erkodur ${ }^{\circledR}$ gemessen worden. Die zum Teil deutlich voneinander abweichenden Kräfte und Drehmomente der untersuchten Materialien wurden durch die statistische Untersuchung mit Paarvergleichen belegt. Abgesehen von den Paarvergleichen Biolon $^{\circledR} /$ Ideal Clear $^{\circledR}$ und Erkodur ${ }^{\circledR} /$ Ideal Clear $^{\circledR}$ wiesen alle Vergleiche für Fz und Tz für die Auslenkungsstrecken $0,360 \mathrm{~mm}$ und $-0,360 \mathrm{~mm}$ statistische Signifikanzen auf. Für die niedrigen Auslenkungsstrecken $(0,157 \mathrm{~mm}$ und $-0,157 \mathrm{~mm})$ hingegen konnten die Unterschiede in der Kraft- und Drehmomentabgabe bei den verschiedenen Materialien statistisch 
nicht eindeutig belegt werden. Die Paarvergleiche zeigten hier nur für die Drehmomente (Tz) signifikant unterschiedliche Werte.

Zur Klärung der Frage, aus welchem Grund unterschiedliche Schienenmaterialien gleicher Stärke statistisch signifikant unterschiedlich hohe Kräfte und Drehmomente erzeugen, liegt die Betrachtung der Zusammensetzung der untersuchten Materialien nahe.

Biolon $^{\circledR}$ besteht aus einem Polyethylenterephthalat (PET). Erkodur ${ }^{\circledR}$-Schienen werden wiederum aus einem glykolmodifizierten Polyethylenterephthalat (PETG) hergestellt. Für die Herstellung von Ideal Clear ${ }^{\circledR}$ - und Ideal Comfort ${ }^{\circledR}$-Schienen hingegen wird ein Polyester auf Terephthalatsäurebasis verwendet. Die Schienenmaterialien unterscheiden sich neben der Zusammensetzung auch in ihren Elastizitätsmodulen. Der Elastizitätsmodul (E-Modul) ist eine Materialkonstante und wird auch als Dehnungsmodul bezeichnet (Harms 2000). Er beschreibt den Zusammenhang zwischen der Spannung und der Dehnung bei der Verformung eines festen Körpers. Je mehr Widerstand ein Material seiner Verformung entgegensetzt, umso größer ist sein Elastizitätsmodul (Marxkors et al. 2008). Folglich applizieren Materialien mit einem höheren E-Modul höhere Kräfte. Der Elastizitätsmodul variiert für die untersuchten Materialien zwischen 2000 N/mm und 2050 N/mm. Ideal Comfort $^{\circledR}$ weist das geringste E-Modul von $2000 \mathrm{~N} / \mathrm{mm}$ auf. Der E-Modul für Biolon ${ }^{\circledR}$ und Erkodur $^{\circledR}$ liegt bei $2050 \mathrm{~N} / \mathrm{mm}$. Von einem direkten Zusammenhang zwischen Materialeigenschaften und applizierter Kraft kann demzufolge ausgegangen werden. Dieser müsste im klinischen Alltag ebenfalls mitberücksichtigt und einkalkuliert werden.

Der bedeutendste Einfluss auf die Kraftabgabe wird in den Herstellungsverfahren der Schienen vermutet. Die Schienen wurden mit unterschiedlichen Geräten hergestellt, die mit verschiedenen Tiefziehtechniken arbeiten. $\mathrm{Zu}$ unterscheiden sind Vakuum- von Druckformgeräten. Die Technik zur Herstellung der Erkodur ${ }^{\circledR}-$, Ideal Clear ${ }^{\circledR}$ - und Ideal Comfort ${ }^{\circledR}$ Schienen arbeitet mit Vakuum. Dabei entsteht ein Druck von 0,8 bar. Das Druckformgerät zur Herstellung der Biolon ${ }^{\circledR}$-Schienen presst das erwärmte Schienenmaterial auf das Modell und erzeugt dabei einen Überdruck von bis zu 6 bar. Es ist anzunehmen, dass durch die Druckformtechnik eine präzisere Passform der Biolon ${ }^{\circledR}$-Schienen erreicht wird. Folglich kommt es zu höheren Friktionskräften im Seitenzahnbereich, die über die resultierenden Rückstellkräfte maßgeblich an der Erzeugung intrusiver Kräfte beteiligt sind.

Diese These unterstützend, weisen die Erkodur ${ }^{\circledR}$-Schienen folgende Besonderheit auf, die sich negativ auf die Schienenpassform auswirken könnte. Nach dem Tiefziehvorgang der Erkodur $^{\circledR}$-Schienen wird eine $0,05 \mathrm{~mm}$ dicke Zwischenfolie von der den Zähnen zugewandten 
Seite entfernt. Dadurch könnte eine geringere Passgenauigkeit der Schienen vermutet werden. Die insgesamt vergleichsweise niedrigen Messwerte für Erkodur ${ }^{\circledR}$ bestätigen die Vermutung. Fraglich ist aber, ob sich eine 0,05 mm dünne Folie, die während des Tiefziehvorganges zusätzlich ausgedünnt wird, negativ auf die Präzision der Passform auswirkt (Hahn 2009).

Die statistischen Paarvergleiche der Biolon ${ }^{\circledR}-S c h i e n e n$ mit den anderen untersuchten Materialien waren nicht immer signifikant, so dass die oben aufgestellte These statistisch nicht eindeutig belegt werden konnte. Die Ergebnisse können aber als ein deutlicher Hinweis auf einen Zusammehang zwischen Kraftabgabe und Herstellungverfahren interpretiert werden. 


\section{Zusammenfassung}

Zur Korrektur von Zahnfehlstellungen werden neben vielen anderen orthodontischen Apparaturen auch thermoplastisch geformte Schienen eingesetzt. Der Indikationsbereich für die Behandlung mit Alignern ist limitiert. Es konnte aber gezeigt werden, dass die Frontzahnrotation, die in der vorliegenden Arbeit untersucht wurde, erfolgreich mit Schienen durchgeführt werden kann (Hensel et al. 2003, Schmeil und Hirschfelder 2004, Kravitz et al. 2008). Unabhängig von der gewählten Apparatur sollten für eine ideale orthodontische Therapie Kräfte eingesetzt werden, die eine maximale Zahnbewegung bei möglichst geringem Gewebeschaden bewirken (Kwon et al. 2008). Um diesem Anspruch gerecht zu werden, ist die Kenntnis über die eingesetzte Kraftgröße unumgänglich. Über die komplexe Biomechanik der Schienentherapie existieren bisher nur wenige Untersuchungen. In der vorliegenden Studie wurden deshalb Kraft- und Drehmomentmessungen mit einer neu entwickelten Invitro-Messapparatur durchgeführt. Es wurden die initialen intrusiven Kräfte (Fz) und Drehmomente $(\mathrm{Tz})$ gemessen, die bei der Rotation eines Unterkieferfrontzahnes von Alignern aus verschiedenen Materialien $\left(\right.$ Biolon $^{\circledR}$, Erkodur $^{\circledR}$, Ideal $_{\text {Clear }}{ }^{\circledR}$ und Ideal Comfort $^{\circledR}$ ) erzeugt wurden. Im Besonderen wurde der Einfluss der Auslenkungsstrecke $(0,157 \mathrm{~mm},-0,157 \mathrm{~mm}$, 0,360 mm, $-0,360 \mathrm{~mm}$ ) und des Schienenmaterials betrachtet.

Die als Nebeneffekt auftretenden intrusiven Kräfte und die therapierelevanten Drehmomente überschritten die empfohlenen Werte deutlich. Die tendenziell höchsten Werte für Fz und $\mathrm{Tz}$ applizierte das Material Biolon ${ }^{\circledR}$. Ideal Comfort $^{\circledR}$ applizierte bei höherer Auslenkungsstrecke statistisch signifikant niedrigere Kräfte und Drehmomente als die anderen drei Materialien. Mögliche Erklärungsansätze für diese Beobachtung könnten die Materialeigenschaften und das Herstellungsverfahren der Schienen sein.

Bei der Rotationsrichtung des Messzahnes mit dem Uhrzeigersinn wurden niedrigere Drehmomente gemessen als in entgegengesetzter Rotationsrichtung. Neben der Zahnmorphologie wird eine Materialermüdung durch mechanische Belastung als Erklärung angenommen.

Für ein genaueres Verständnis der biomechanischen Hintergründe in der orthodontischen Therapie mit thermoplastisch geformten Schienen sind weitere biomechanische und klinische Untersuchungen erforderlich. Die in dieser Arbeit gewonnenen Werte könnten als valide Vergleichswerte herangezogen werden. 


\section{Literaturverzeichnis}

Acar A, Canyürek U, Kocaaga M, Erverdi N (1999): Continuous vs. discontinuous force application and root resorption. Angle Orthod 69(2), 159-163

Alhashimi N, Frithiof L, Brudvik P, Bakhiet M (2001): Orthodontic tooth movement and de novo synthesis of proinflammatory cytokines. Am J Orthod Dentofacial Orthop 119(3), 307312

Apajalathi S, Peltola JS (2007): Apical root resorption after orthodontic treatment - a retrospective study. Eur J Orthod 29(4), 408-412

Baccetti T, Franchi L, Camporesi M (2008): Forces in the presence of ceramic versus

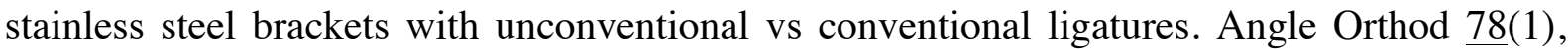
$120-124$

Barbagallo LJ, Shen G, Jones AS, Swain MV, Petocz P, Darendeliler MA (2008a): A Novel Pressure Film Approach for Determining the Force Imparted by Clear Removable Thermoplastic Appliances. Ann Biomed Eng 36(2), 335-341

Barbagallo LJ, Jones AS, Petocz P, Darendeliler MA (2008b): Physical properties of root cementum: Part 10. Comparison of the effects of invisible removable thermoplastic appliances with light and heavy orthodontic forces on premolar cementum. A microcomputed-tomography study. Am J Orthod Dentofacial Orthop 133(2), 218-227

Bartzela TN, Senn C, Wichelhaus A (2007): Load-deflection characteristics of superelastic nickel-titanium wires. Angle Orthod 77(6), 991-998

Beck BW, Harris EF (1994): Apical root resorption in orthodontically treated subjects: Analysis of edgewise and light wire mechanics. Am J Orthod Dentofacial Orthop 105(4), 350-361 
Bollen A-M, Huang G, King G, Hujoel P, Ma T (2003): Activation time and material stiffness of sequential removable orthodontic appliances. Part 1: Ability to complete treatment. Am J Orthod Dentofacial Orthop 124(5), 496-501

Boyd RL (2008): Esthetic Orthodontic Treatment Using the Invisalign Appliance for Moderate to Complex Malocclusions. J Dent Educ 72(8), 948-967

Boyd RL, Vlascalic V (2001): Three-Dimensional Diagnosis and Orthodontic Treatment of Complex Malocclusions With the Invisalign Appliance. Semin Orthod 7(4), 274-293

Boyd RL, Miller RJ, Vlaskalic V (2000): The Invisalign system in adult orthodontics: mild crowding and space closure case. J Clin Orthod 34(4), 203-212

Böhl M von, Kuijpers-Jagtman AM (2009): Hyalinization during orthodontic tooth movement: a systematic review on tissue reactions. Eur J Orthod 31, 30-36

Brezniak N (2008): The Clear Plastic Appliance: A Biomechanical Point of View. Angle Orthod $\underline{78}(2), 381-382$

Brezniak N, Wasserstein A (2002): Orthodontically Induced Inflammatory Root Resorption. Part 1: The Basic Science Aspects. Angle Orthod 72(2), 175-179

Brezniak N, Wasserstein A (2008): Root Resorption Following Treatment with Aligners. Case Report. Angle Orthod 78(6), 1119-1124

Brudvik P, Rygh P (1994): Multi-nucleated cells remove the main hyalinized tissue and start resorption of adjacent root surfaces. Eur J Orthod 16(4), 265-273

Brudvik P, Rygh P (1995): Transition and determinants of orthodontic root resorption-repair sequence. Eur J Orthod 17(3), 177-88

Burstone CJ, Pryputniewicz RJ (1980): Holographic determination of centers of rotation produced by orthodontic forces. Am J Orthop 77(4), 396-409 
Burstone CJ, Pryputniewicz RJ (1981): Centers of resistance of the human mandibular molars. J Dent Res $\underline{60}, 515$

Casa MA, Faltin RM, Faltin K, Sander FG, Arana-Chavez VE (2001): Root Resorptions in Upper First Premolars after Application of Continuous Torque Moment. Intra-individual study. J Orofac Orthop 62(4), 285-295

Chenin DA, Trosien AH, Fong PF, Miller RA, Lee RS (2003): Orthodontic treatment with a series of removable appliances. J Am Dent Assoc 134(9), 1232-1239

Christensen GJ (2002): Orthodontics and the general practitioner. J Am Dent Assoc 133(3), 369-371

Coolidge E (1937): The thickness of the human periodontal membrane. J Am Dent Assoc 24 , $1260-1265$

Dermaut LR, De Munck A (1986): Apical root resorption of upper incisors by intrusive tooth movement: a radiographic study. Am J Orthod Dentofacial Orthop 90(4), 321-326

Diedrich P (1990): Biomechanische Prinzipien für orthodontische Bewegungen bei reduziertem Attachment. Dtsch Zahnaerztl Zeitschr 45, 78-81

Djeu G, Shelton C, Maganzini A (2005): Outcome assessment of Invisalign and traditional orthodontic treatment compared with the American Board of Orthodontics objective grading system. Am J Orthod Dentofacial Orthop 128(3), 292-298

Dorow C, Krstin N, Sander FG (2002): Experiments to determine the material properties of the periodontal ligament. J Orofac Orthop 63(2), 94-104

Dorow C, Krstin N, Sander FG (2003): Determination of the mechanical properties of the periodontal ligament in a uniaxial tensional experiment. J Orofac Orthop 64(2), 100-107 
Dos Santos Junior J, de Rijk WG (1993): Occlusal contacts: vectorial analysis of forces transmitted to temporomandibular joint and teeth. Cranio 11(2), 118-125

Dougherty HL (1968): The effect of mechanical forces upon the mandibular buccal segments during orthodontic treatment. Am J Orthod 54(2), 83-103

Eichner K (1963): Messung der Kräfte bei Kauvorgängen. Dtsch Zahnärztl Z 18(17), 915-924

Engelke B: Kraft- und Drehmomentabgabe thermoplastisch geformter Schienen bei Frontzahnderotation vor und nach Alterungssimulation. Med. Diss. Göttingen 2010

Erfurth-Jach TF: Biomechanische Untersuchungen an thermoplastisch geformten Schienen. Med. Diss. Göttingen 2012

Faltin RM, Arana-Chavez VE, Faltin K, Sander FG, Wichelhaus A (1998): Root resorptions in upper first premolars after application of continuous intrusive forces. Intra-individual study. J Orofac Orthop 59(4), 208-219

Faltin RM, de Almeida MAA, Kessner CA, Faltin K (2003): Efficiency, three-dimensional planning and prediction of the orthodontic treatment with the Invisalign System: case report. R Clin Ortodon Dental Press $\underline{2}, 61-71$

Farrar JN (1867): An inquiry into physiological and pathological changes in animal tissues in regulating teeth. Dent Cosmos $\underline{18}(1), 13-24$

Giancotti A, Greco M, Mampieri G (2006): Extraction treatment using Invisalign ${ }^{\circledR}$ Technique. Prog Orthod $\underline{7}(1), 32-43$

Göz G: Kraft und Kraftdauer; in Kieferorthopädie Band 2; hrsg. v. Diedrich P; 4. Auflage, Urban \& Fischer Verlag, München Jena 2000

Hahn W: Kraft-Drehmomentabgabe und Biomechanik thermoplastisch geformter Schienen zur orthodontischen Zahnbewegung. Med. Habil.-Schr. Göttingen 2009 
Hahn W, Fialka-Fricke J, Dathe H, Fricke-Zech S, Zapf A, Gruber R, Kubein-Meesenburg D, Sadat-Khonsari R (2009a): Initial forces generated by three types of thermoplastic appliances on an upper central incisor during tipping. Eur J Orthod 31(6), 625-631

Hahn W, Dathe H, Fialka-Fricke J, Fricke-Zech S, Zapf A, Kubein-Meessenburg D, SadatKhonsari R (2009b): Influence of thermoplastic appliance thickness on the magnitude of force delivered to a maxillary central incisor during tipping. Am J Orthod Dentofacial Orthop $\underline{136}(1), 12 \mathrm{e} 1-7$, discussion 12-3

Hahn W, Engelke B, Jung K, Dathe H, Fialka-Fricke J, Kubein-Meesenburg D, SadatKhonsari D (2010a): Initial forces and moments delivered by removable thermoplastic appliances during rotation of an upper central incisor. Angle Orthod $\underline{80}(2), 239-246$

Hahn W, Zapf A, Dathe H, Fialka-Fricke J, Fricke-Zech S, Gruber R, Kubein-Meessenburg D, Sadat-Khonsari R (2010b): Torquing an upper central incisor with aligners-acting forces and biomechanical principles. Eur J Orthod 32(6), 607-613

Hahn W, Engelke B, Jung K, Dathe H, Kramer FJ, Rödig T, Kubein-Meessenburg D, Gruber RM (2011): The influence of occlusal forces on force delivery properties of aligners during rotation of an upper central incisor. Angle Orthod $\underline{81}(6), 1057-1063$

Harms V: Physik für Mediziner und Pharmazeuten. 15. neu bearbeitete Auflage; Harms Verlag, Lindhöft 2000

Harris DA, Jones AS, Darendeliler MA (2006): Physical properties of root cementum: Part 8. Volumetric analysis of root resorption craters after application of controlled intrusive light and heavy orthodontic forces: A microcomputed tomography scan study. Am J Orthod Dentofacial Orthop 130(5), 639-647

Hartsfield JK Jr., Everetett ET, Al-Qawasmi RA (2004): Genetic factors in external apical root resorption and orthodontic treatment. Crit Rev Oral Biol Med 15(2), 115-122 
Hensel E, Born G, Körber V, Altvater T, Gesch D (2003): Prevalence of Defined Symptoms of Malocclusion among Probands Enrolled in the Study of Health in Pomerania (SHIP) in the Age Group from 20 to 49 Years. J Orofac Orthop 64(3), 157-166

Hohmann A, Wolfram U, Geiger M, Boryor A, Sander C, Faltin R, Faltin K, Sander FG (2007): Periodontal Ligament Hydrostatic Pressure with Areas of Root Resorption after Application of a Continuous Torque Moment. Angle Orthod 77(4), 653-659

Jepsen A (1963): Root surface measurement and a method for x-ray determination of surface area. Acta Odontol Scand 21, 35-46

Joffe L (2003): Invisalign: early experiences. J Orthod 30(4), 348-352

Kahl-Nieke B: Einführung in die Kieferorthopädie. 2. Auflage, Urban \& Fischer Verlag, München 2001 (eine Publikationserlaubnis für die Abb. 19-4 liegt vor)

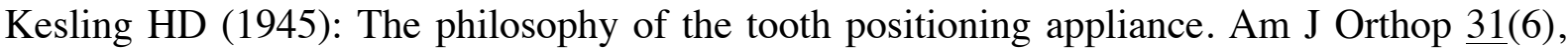
297-304

Kravitz ND, Kusnoto B, Agran B, Viana G (2008): Influence of Attachments and Interproximal Reduction on the Accuracy of Canine Rotation with Invisalign. Angle Orthod $\underline{78}(4), 682-687$

Kubein D, Jäger A, Bormann V (1984): Systematik der Distalisation oberer Sechser mit dem indirekten Headgear. Fortschr Kieferorthop 45 (2), 128-140

Kwon JS, Lee JK, Lim BS, Lim YK (2008): Force delivery properties of thermoplastic orthodontic materials. Am J Orthod Dentofacial Orthop 133(2), 228-234

Lagravère MO, Flores-Mir C (2005): The treatment effects of Invisalign orthodontic aligners: a system review. J Am Dent Assoc 136(12), 1724-1729

Lehmann KM, Hellwig E: Zahnärztliche Propädeutik, 9. Auflage; Urban\&Fischer, München 2002 
Levander E, Malmgren O (1988): Evaluation of the risk of root resorption during orthodontic treatment: A study of upper incisors. Eur J Orthod 10(1), 30-38

Levander E, Malmgren O, Eliasson S (1994): Evaluation of root resorption in relation to two orthodontic treatment regimes. A clinical experimental study. Eur J Orthod 16(3), 223-228

Lim Y, Quick A, Swain M, Herbison P (2008): Temperature Effects on the Forces, Moments and Moment to Force Ratio of Nickel-Titanium and TMA Symmetrical T-loops. Angle Orthod $\underline{78}(6), 1035-1042$

Lindauer SJ, Shoff RC (1998): Comparison of Essix and Hawley retainers. J Clin Orthod 32(2), 95-97

Linge BO, Linge L (1983): Apical root resorption in upper anterior teeth. Eur J Orthod $\underline{5}(3)$, $173-183$

Linge BO, Linge L (1991): Patient characteristics and treatment variables associated with apical root resorption during orthodontic treatment. Am J Orthod Dentofacial Orthop 99(1), $35-43$

Maltha JC, Dijkman GE (1996): Discontinuous forces cause less extensive root resorption than continuous forces. Eur J Orthod 18, 420

Marxkors R, Meiners H, Geis-Gerstorfer J: Taschenbuch der zahnärztlichen Werkstoffkunde. Vom Defekt zur Restauration. 6. Auflage, Deutscher Zahnärzte Verlag, Köln 2008

Masella RS, Meister M (2006): Current concepts in the biology of orthodontic tooth movements. Am J Orthod Dentofacial Orthop 129(4), 458-468

McFadden WM, Engstrom C, Engstrom H, Anholm JM (1989): A study of the relationship between incisor intrusion and root shortening. Am J Orthod Dentofacial Orthop 96(5), 390396 
McNamara JA Jr, Kramer KL, Juenker JP (1985): Invisable retainers. J Clin Orthod 19, 570578

Melsen B, Burstone CJ: The transpalatal arch and the lower lingual arch. Their use as active and passive appliance. In: Melsen B, Burstone Ch: Introduction to biomechanics, Syllabus University of Aarhus, Aarhus 1990

Miller RJ, Duong TT, Derakhshan M (2002): Case Report. Lower Incisor Extraction Treatment with the Invisalign System. J Clin Orthod 36(2), 95-102

Nahoum HI (1964): The vacuum formed dental contour appliance. NY State Dent J $\underline{9}, 385-$ 390

Nedwed V, Miethke RR (2005): Motivation, Acceptance and Problems of Invisalign ${ }^{\circledR}$ Patients. J Orofac Orthop 66(2), 162-173

Nicholls JI, Daly CH, Kydd WL (1974): Root surface mesurement using a digital computer. J Dent Res 53(6), 1338-1341

Oppenheim A (1930): Bone changes during tooth movement. Int J Orthod 16(5), 535-551

Oppenheim A (1942): Human tissue response to orthodontic intervention of short and long duration. Am J Orthod Oral Surg 28(5), 263-301

Pandis N, Eliades T, Partowi S, Bourauel C (2008a): Forces exerted by conventional and selfligating brackets during simulated first- and second-order corrections. Am J Orthod Dentofacial Orthop 133(5), 738-742

Pandis N, Eliades T, Partowi S, Bourauel C (2008b): Moments Generated during Simulated Rotational Correction with Self-Ligating and Conventional Brackets. Angle Orthod 78(6), $1030-1034$

Ponitz RJ (1971): Invisible retainers. Am J Orthop 59(3), 266-271 
Proffit WR: The biological Basis of Orthodontic Therapy; In: Contemporary Orthodontics. 3. Auflage; hrsg. v. Proffit WR, Fields HW; Mosby Year Book Inc, St. Louis 2000

Proffit WR, Fields HW, Nixon WL (1983): Occlusal Forces in Normal- and Long-face Adults. J Dent Res 62(5), 566-571

Reitan K (1951): The initial tissue reaction incident to orthodontic tooth movement. Acta Odontol Scand $\underline{6}, 194-228$

Reitan K (1960): Tissue behaviour during orthodontic tooth movement. Am J Orthop 46(12), $881-900$

Reitan K (1964): Effects of force magnitude and direction of tooth movement on different alveolar bone types. Angle Orthod 34(4), 244-255

Reitan K (1967): Clinical and histologic observations on tooth movement during and after orthodontic treatment. Am J Orthod 53, 721-745

Remington DN, Joondeph DR, Årtun J, Riedel RA, Chapko MK (1989): Long-term evaluation of root resorption occurring during orthodontic treatment. Am J Orthod Dentofacial Orthop 96(1), 43-46

Ren Y, Maltha JC, Kuijpers-Jagtman AM (2003): Optimum Force Magnitude for Orthodontic Tooth Movement: A Systematic Literature Review. Angle Orthod 73(1), 86-92

Rinchuse DoJ, Rinchuse DaJ (1997): Active tooth movement with Essix based appliances. J Clin Orthod 31(2), 109-112

Roberts WE, Goodwin WC Jr, Heiner SR (1981): Cellular response to orthodontic force. Dent Clin North Am 25, 3-17

Roberts WE, Turley PK, Brezniak N, Fiedler PJ (1987): Bone physiology and metabolism. J Calif Dent Assoc J 15, 54-61 
Rosenbauer KA, Engelhardt JP, Koch H, Stüttgen U: Klinische Anatomie der Kopf- und Halsregion für Zahnmediziner. Thieme Verlag, Stuttgart 1998

Rost D, Schwarze CW, Hilgers RD (1995): Die Kraftabgabe von Positionern bei unterschiedlicher Schneidezahnprotrusion. Eine In-vitro-Untersuchung. Fortschr Kieferorthop $\underline{56}(2), 104-109$

Rygh P (1973): Ultrastructural changes in pressure zones of human periodontium incident to orthodontic tooth movement. Acta Odontol Scand 31, 109-122

Sameshima GT, Sinclair PM (2001): Predicting and preventing root resorption: Part 1.

Diagnostic factors. Am J Orthod Dentofacial Orthop 119(5), 505-510

Schmeil F, Hirschfelder U: Kieferorthopädische Zahntechnik. Neuer Merkur Verlag GmbH, München 2004

Schopf P : Curriculum Kieferorthopädie, Band I und III, 3. Auflage; Quintessenz VerlagsGmbH, Berlin 2000

Schwarz AM (1932): Tissue changes incidental to orthodontic tooth movement. Int J Orthodont $\underline{18}, 331-352$

Seiffert SA: Kraftabgabe thermoplastisch geformter Schienen mit inzisaler Schlitzung zur orthodontischen Zahnbewegung. Med. Diss. Göttingen 2012

Sheridan JJ, Ledoux W, McMinn R (1993): Essix Retainers: Fabrication and Supervision for Permanent Retention. J Clin Orthod 27(1), 37-45

Sheridan JJ, LeDoux W, McMinn R (1994): Minor tooth movement with divots and windows. J Clin Orthod, 28 (11), 659-663

Smith RJ, Burstone CJ (1984): Mechanics of tooth movement. Am J Orthop 85(4), 294-307 
Vlaskalic V, Boyd RL (2002): Clinical Evolution of the Invisalign Appliance. J Calif Dent Assoc 30(10), 769-776

Vlaskalic V, Boyd RL, Hordt C, Miethke RR (2001): Die kieferorthopädische Behandlung mit dem Invisalign ${ }^{\circledR}$-System. Kieferorthopädie Sonderheft Invisalign, 17-24

Walker MP, Ries D, Kula K, Ellis M, Fricke B (2007): Mechanical properties and surface characterization of beta titanium and stainless steel orthodontic wire following topical fluoride treatment. Angle Orthod 77(2), 342-348

Wang T, Zhou G, Tan X, Dong Y (2007): Evaluation of force degradation characteristics of orthodontic latex elastics in vitro and in vivo. Angle Orthod 77(4), 688-693

Warunek SP, Sorensen SE, Cunat JJ, Green LJ (1989): Physical and mechanical properties of elastomers in orthodontic positioners. Am J Orthod Dentofacial Orthop 95(5), 388-400

Weiland F (2003): Constant versus dissipating forces in orhtodontics: the effect on initial tooth movement and root resorption. Eur J Orthod 25(4), 335-342

Witt E, Timper E (1974): Experimentelle Untersuchungen über Schluckdauer und Schluckhäufigkeit bei Kindern und Erwachsenen mit verschiedenen Anomalien. J Orofac Orthop 35(4), 306-322

Wong BH (2002): Invisalign A to Z. Am J Orthod Dentofacial Orthop 121(5), 540-541 


\section{Danksagung}

Besonderer Dank gilt meinem Doktorvater Herrn PD Dr. med. dent. Wolfram Hahn, der meine Arbeit mit viel Engagement begleitet hat. Sein präzises wissenschaftliches und praktisches Arbeiten wird mich nachhaltig prägen.

Herzlich bedanken möchte ich mich auch bei Herrn Dr. Benjamin Engelke, der die Vorarbeit zu dieser Arbeit geleistet hat. Er hatte stets wertvolle Ratschläge und motivierte mich, diese Arbeit fertig zu stellen.

Außerdem möchte ich mich bei den Mitarbeitern der Abteilung Kieferorthopädie der Universität Göttingen bedanken. 